\title{
Are Young Swimmers Short and Middle Distances Energy Cost Sex-Specific?
}

\author{
Danilo A. Massini', Tiago A. F. Almeida',3, Camila M. T. Vasconcelos', \\ Anderson G. Macedo ${ }^{1,2}$, Mário A. C. Espada ${ }^{4,5}$, Joana F. Reis ${ }^{3,6}$, Francisco J. B. Alves ${ }^{3,6}$, \\ Ricardo J. P. Fernandes ${ }^{7}$ and Dalton M. Pessôa Filho',2* \\ ' Postgraduate Programme in Human Development and Technologies, São Paulo State University - UNESP, Rio Claro, \\ Brazil, ${ }^{2}$ São Paulo State University - UNESP, Bauru, Brazil, ${ }^{3}$ CIPER, Faculdade de Motricidade Humana, University \\ de Lisboa, Lisbon, Portugal, ${ }^{4}$ School of Education (CIEF - CDP2T), Polytechnic Institute of Setúbal, Setúbal, Portugal, \\ ${ }^{5}$ Quality of Life Research Centre (CIEQV - Politécnico de Leiria), Leiria, Portugal, ${ }^{6}$ Faculdade de Motricidade Humana, \\ Universidade de Lisboa, Lisbon, Portugal, ${ }^{7}$ Faculty of Sport, Centre of Research, Education, Innovation and Intervention \\ in Sport, University of Porto, Porto, Portugal
}

This study assessed the energy cost in swimming $(\mathrm{C})$ during short and middle distances to analyze the sex-specific responses of $\mathrm{C}$ during supramaximal velocity and whether body composition account to the expected differences. Twenty-six swimmers (13 men and 13 women: $16.7 \pm 1.9$ vs. $15.5 \pm 2.8$ years old and $70.8 \pm 10.6$ vs. $55.9 \pm 7.0 \mathrm{~kg}$ of weight) performed maximal front crawl swimming trials in 50, 100, and $200 \mathrm{~m}$. The oxygen uptake $\left(\mathrm{VO}_{2}\right)$ was analyzed along with the tests (and post-exercise) through a portable gas analyser connected to a respiratory snorkel. Blood samples were collected before and after exercise (at the 1st, 3rd, 5th, and 7th min) to determine blood lactate concentration $\left[\mathrm{La}^{-}\right]$. The lean mass of the trunk ( $\left(\mathrm{M}_{\text {Trunk }}\right)$, upper limb (LM $\left.\mathrm{LML}_{\mathrm{L}}\right)$, and lower limb $\left(L M_{L L}\right)$ was assessed using dual X-ray energy absorptiometry. Anaerobic energy demand was calculated from the phosphagen and glycolytic components, with the first corresponding to the fast component of the $\mathrm{V}_{2}$ bi-exponential recovery phase and the second from the $2.72 \mathrm{ml} \times \mathrm{kg}^{-1}$ equivalent for each $1.0 \mathrm{mmol} \times \mathrm{L}^{-1}$ [ $\mathrm{La}^{-}$] variation above the baseline value. The aerobic demand was obtained from the integral value of the $\mathrm{VO}_{2}$ vs. swimming time curve. The $\mathrm{C}$ was estimated by the rate between total energy releasing (in Joules) and swimming velocity. The sex effect on $\mathrm{C}$ for each swimming trial was verified by the two-way ANOVA (Bonferroni post hoc test) and the relationships between $L M_{\text {Trunk }}$, $L M_{U L}$, and $L M_{L L}$ to $C$ were tested by Pearson coefficient. The $C$ was higher for men than women in 50 (1.8 $\left.\pm 0.3 \mathrm{vs} .1 .3 \pm 0.3 \mathrm{~kJ} \times \mathrm{m}^{-1}\right), 100(1.4 \pm 0.1 \mathrm{vs}$ $\left.1.0 \pm 0.2 \mathrm{~kJ} \times \mathrm{m}^{-1}\right)$, and $200 \mathrm{~m}\left(1.0 \pm 0.2 \mathrm{vs}\right.$. $\left.0.8 \pm 0.1 \mathrm{~kJ} \times \mathrm{m}^{-1}\right)$ with $p<0.01$ for all comparisons. In addition, $\mathrm{C}$ differed between distances for each $\operatorname{sex}(p<0.01)$. The regional $L_{\text {Trunk }}(26.5 \pm 3.6$ vs. $20.1 \pm 2.6 \mathrm{~kg})$, LM $\mathrm{ML}_{L}(6.8 \pm 1.0 \mathrm{vs.} 4.3 \pm 0.8 \mathrm{~kg})$, and $\operatorname{LM}_{L L}(20.4 \pm 2.6 \mathrm{vs} .13 .6 \pm 2.5 \mathrm{~kg})$ for men vs. women were significantly correlated to $\mathrm{C}$ in $50\left(R^{2}\right.$ adj $\left.=0.73\right), 100\left(R^{2}\right.$ adj $\left.=0.61\right)$, and $200 \mathrm{~m}\left(R^{2}\right.$ adj $\left.=0.60, p<0.01\right)$. Therefore, the increase in $\mathrm{C}$ with distance is higher for men than women and is determined by the lean mass in trunk and upper and lower limbs independent of the differences in body composition between sexes.

Keywords: oxygen uptake, energy demand, swimming performance, body composition, sex 


\section{INTRODUCTION}

Swimming energy cost (C) expresses the effectiveness of a motor task, allowing the analysis of the motor ability to save or enhance energy production and reflect skilled performance level and muscular work capacity (respectively) from low to high swimming intensities (Fernandes et al., 2006; Zamparo et al., 2008, 2011; Gonjo et al., 2018). In a front crawl, C increases

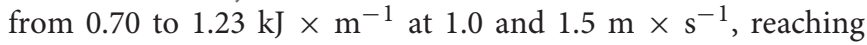
$2.20 \mathrm{~kJ} \times \mathrm{m}^{-1}$ at $2 \mathrm{~m} \times \mathrm{s}^{-1}$ among elite male swimmers (Capelli et al., 1998). The alteration from low to high velocities in swimming requires both muscle power output and energy release to be increased proportionally. Therefore, $\mathrm{C}$ defines how mechanical and metabolic capabilities interact to enhance swimming velocity and tolerance according to swimmer sexgroup, training status (Toussaint and Hollander, 1994; Capelli et al., 1998; Fernandes et al., 2005, 2006), technical level, and swimming stroke technique (di Prampero et al., 2008; Gonjo et al., 2018).

In elite male swimmers, the energy requirements reach $\sim 3.33$, $\sim 2.72$, and $\sim 1.94 \mathrm{~kW}$ at $45.7,91.4$, and $182.9 \mathrm{~m}$ in a front

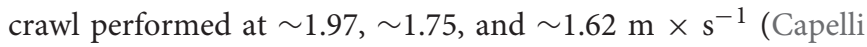
et al., 1998). However, the energy requirements attained $\sim 3.16$, $\sim 1.86$, and $\sim 1.25 \mathrm{~kW}$ for young swimmers from both sexes performing 50,100 , and $200 \mathrm{~m}$ in a front crawl at $\sim 1.67, \sim 1.46$,

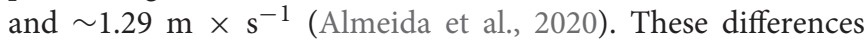
in energy contributions and swimming performances would probably rely on the swimmers' technical and conditioning levels (Fernandes et al., 2006). Muscle mass and fiber composition can also account to those differences, since muscle strength, anaerobic power, and reliance on glycolytic motor units are age group performance influencing factors in short distance swimming races (Hellard et al., 2018).

It is reasonable to consider the amount of muscle mass involved in an exercise with a reliable index of the energetic contribution during a high intensity performance. This is due to how the potential of metabolic resources to the energy releasing can be scaled in body size units, e.g., 0.418 $\mathrm{kJ} \times \mathrm{kg}^{-1}$ for phosphocreatine, $0.0689 \mathrm{~kJ} \times \mathrm{mmol}^{-1} \times \mathrm{kg}^{-1}$ for blood lactate accumulation, and $0.125 \mathrm{~kJ} \times \mathrm{kg}^{-1}$ for $\mathrm{O}_{2}$ stored in arterial blood, i.e., $\sim 6 \mathrm{ml} \times \mathrm{kg}^{-1}$ (Medbo et al., 1988). Nevertheless, other key attributes beyond larger muscle mass to anaerobic releasing are greater fast-type muscle fiber composition (enhancing enzymatic lactate dehydrogenase inhibition/activation rulers and redox potential) and glycogen source, which differ between sexes (Esbjörnsson et al., 1993; Esbjörnsson-Liljedahl et al., 1999).

These differences can reflect the advantage in power production by the body region wherein lean mass is larger, e.g., for upper limbs, when comparing men to women (Weber et al., 2006). In swimming, studies corroborating the role of lean mass on high intensity exercise performance have demonstrated that lean mass in upper-limbs correlates with the maximal aerobic velocity, the velocity at $200 \mathrm{~m}$ races, and anaerobic reserve estimates among young men (Pessôa Filho et al., 2016). In addition, the highest muscle mass in upper and lower limbs is associated with higher aerobic and anaerobic release during performances lasting 2-3 min among swimmers of both sexes (Ogita et al., 1996). Furthermore, the $400 \mathrm{~m}$ front crawl swimming performance peak $\mathrm{VO}_{2}$ and $\mathrm{C}$ differed between prepubertal and pubertal male swimmers, which was a result that can be explained considering the differences in anthropometrical variables, including lean mass (Jürimäe et al., 2007).

However, while adenosine triphosphate turnover requirements of short to middle swimming distances (e.g., 50,100 , and $200 \mathrm{~m}$ ) are preconized to rely on large anaerobic metabolism demand, with aerobic contribution rising in proportionality to distance-trial length (Almeida et al., 2020), the assumptions for the sex-specific response regarding $\mathrm{C}$ and the role of lean mass is lacking. $\mathrm{C}$ values for both sexes have been reported for maximal and supramaximal velocities (Zamparo et al., 2000) but the values of $C$ were measured at 1.2, 1.4, and $1.6 \mathrm{~m} \times \mathrm{s}^{-1}$, which were not necessarily velocities corresponding to 50,100 , and $200 \mathrm{~m}$ trial performances for all tested swimmers. In addition, the reasons explaining the $\mathrm{C}$ differences between sexes at these swimming intensities remain elusive.

Therefore, the association between velocity and energy supply, having sex-based factors as a rule, would evidence a limited rate of energy release for a specific metabolic pathway due to muscle mass difference, even when technical and conditioning levels remain constant. The lack of studies comparing male and female swimmers underappreciated the role of regional and whole-body composition on race performance and swimming training specificity for men and women. Moreover, considering the specific $\mathrm{C}$ values during short (50 and $100 \mathrm{~m}$ ) and middle distances swimming efforts $(200 \mathrm{~m})$, the sex differences regarding regional and whole-body lean mass would expect to have an important role. The current study aimed to analyze the $\mathrm{C}$ sexspecific responses during supramaximal velocity and if body composition account to the expected differences.

\section{MATERIALS AND METHODS}

Twenty-six swimmers participated in the current study (13 men and 13 women with $16.7 \pm 1.9$ vs. $15.5 \pm 2.8$ years of age, $178.4 \pm 8.4$ vs. $162.9 \pm 7.6 \mathrm{~cm}$ of height, $70.8 \pm 10.6$ vs. $55.9 \pm 7.0 \mathrm{~kg}$ of weight). All swimmers were regularly engaged in competitive training programs for at least three annual seasons, with a volume of $25 \mathrm{~km} \times$ week $^{-1}$ during the testing application. Their best front crawl performances at the 50, 100, and $200 \mathrm{~m}$ represented $575 \pm 95$ vs. $534 \pm 63,599 \pm 100$ vs. $529 \pm 78$, and $588 \pm 94$ vs. $552 \pm 83$ FINA points for male and female swimmers, respectively. Participants were informed about all the study procedures and experimental risks and signed a written informed consent (or their legal guardians when under 18 years old) prior to the experiments. The current research was conducted according to the Declaration of Helsinki and was approved by the Ethics Committee of the São Paulo State University (Protocol 54372516.3.0000.5398).

The participants performed five tests, all in front crawl and separated by, at least, $24 \mathrm{~h}$ : (i) a $200 \mathrm{~m}$ maximal test to establish the velocities during the incremental step test; (ii) an incremental step test performed in six progressive steps 
A

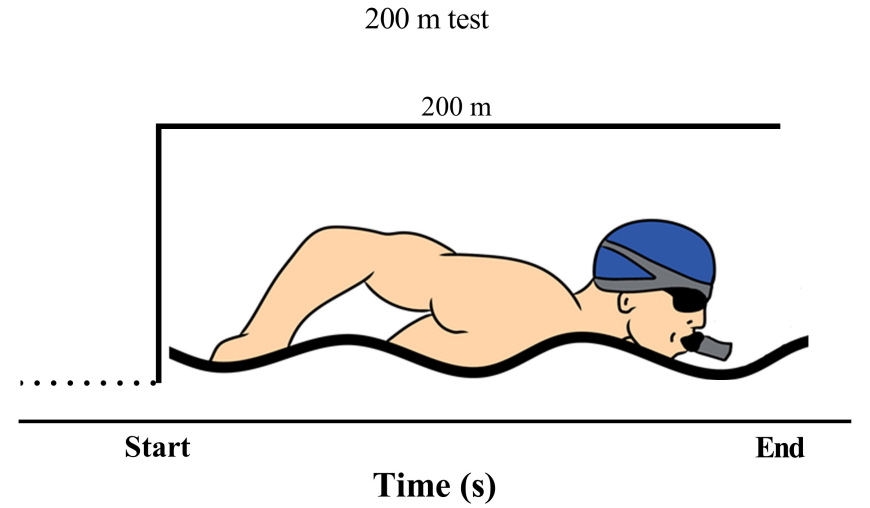

B

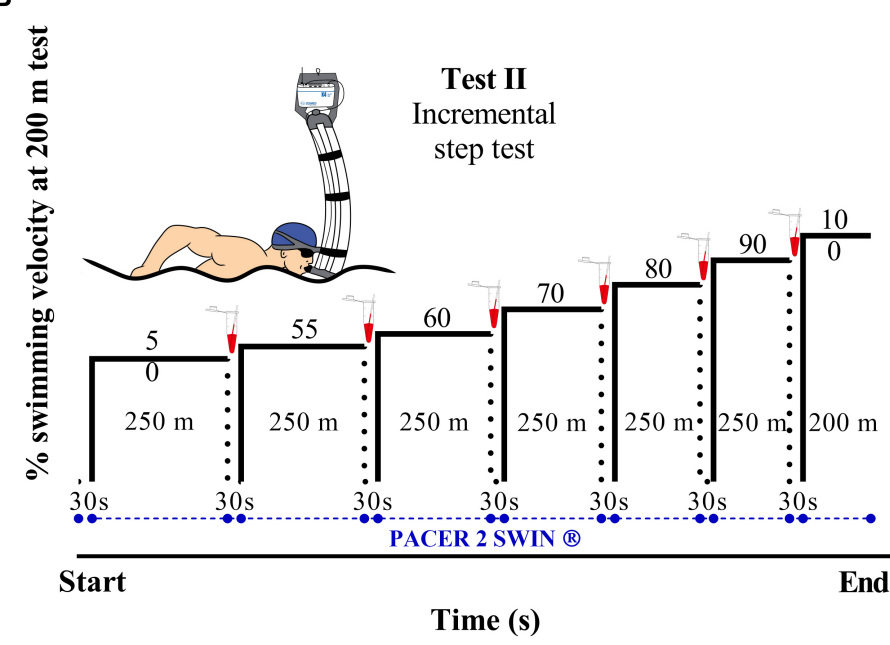

C

\section{Test III}

Performance

trials

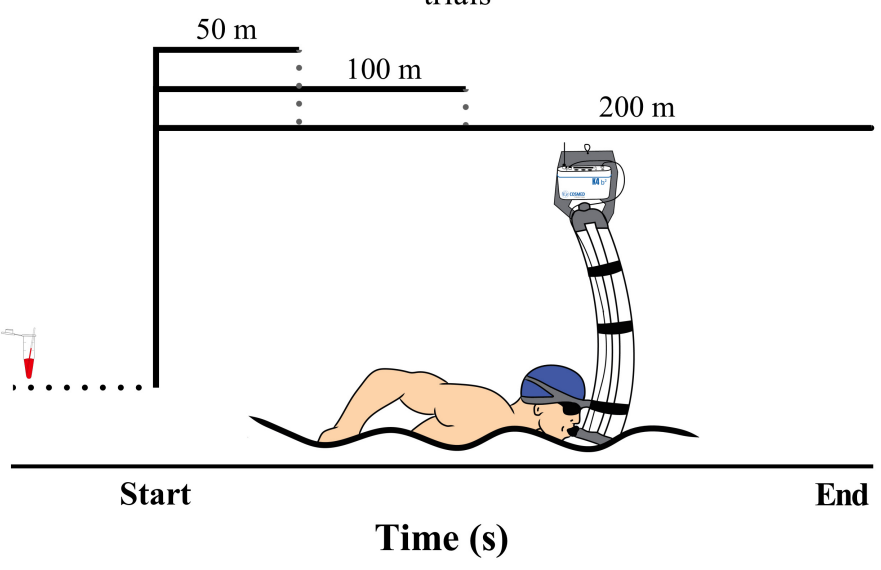

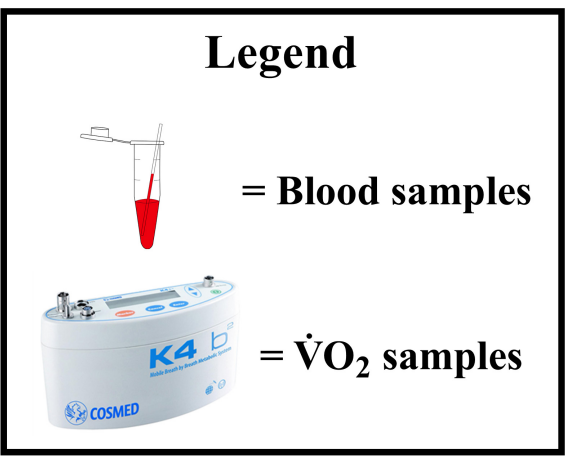

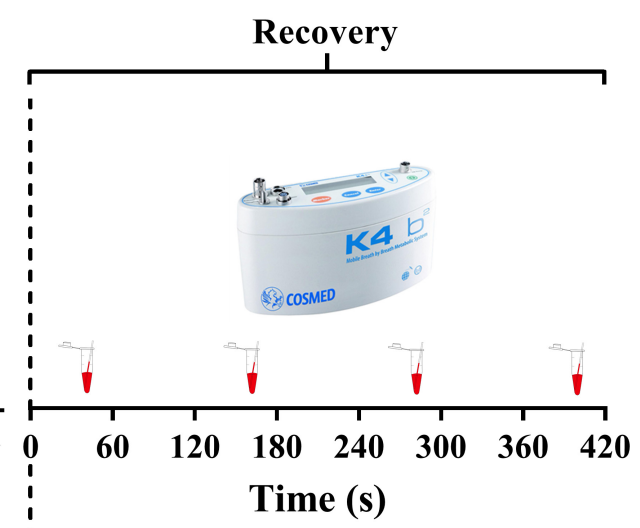

Time (s)

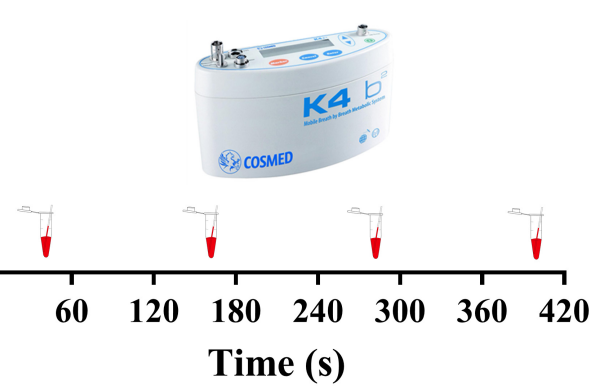

FIGURE 1 | An overview of the experimental protocol. (A) The $200 \mathrm{~m}$ maximal test. (B) The incremental step test. (C) 50 , 100 , and $200 \mathrm{~m}$ maximal trials. 
TABLE 1 | Performance and physiological profiles during short and middle distance races.

\begin{tabular}{|c|c|c|c|}
\hline & \multicolumn{3}{|l|}{ Distances (m) } \\
\hline & 50 & 100 & 200 \\
\hline \multicolumn{4}{|c|}{ Time (s) } \\
\hline Men & $30.0 \pm 2.9$ & $67.5 \pm 5.3^{\text {㧊 }}$ & $159.3 \pm 12.3^{\ddagger \neq \S \S}$ \\
\hline Women & $33.0 \pm 0.5^{\star \star}$ & $71.0 \pm 3.3^{\ddagger \ddagger}$ & $164.1 \pm 8.1 \neq \neq \S \S$ \\
\hline \multicolumn{4}{|c|}{ Velocity $\left(\mathrm{m} \times \mathrm{s}^{-1}\right)$} \\
\hline Men & $1.68 \pm 0.17$ & $1.49 \pm 0.12^{\ddagger \ddagger}$ & $1.26 \pm 0.09^{\ddagger \ddagger} \S \S$ \\
\hline Women & $1.52 \pm 0.07^{\star \star}$ & $1.41 \pm 0.07^{\star \text { 㧊 }}$ & $1.22 \pm 0.06^{\ddagger \ddagger} \S \S$ \\
\hline \multicolumn{4}{|c|}{$[\mathrm{La}-]_{\text {peak }}\left(\mathrm{mmol} \times \mathrm{L}^{-1}\right)$} \\
\hline Men & $9.2 \pm 1.9$ & $11.4 \pm 2.1^{\text {㧊 }}$ & $10.2 \pm 1.8$ \\
\hline Women & $9.8 \pm 1.4$ & $11.6 \pm 1.8^{\ddagger \ddagger}$ & $10.9 \pm 1.4$ \\
\hline \multicolumn{4}{|c|}{ Energy, $\mathrm{EqO}_{2}(\mathrm{~L})$} \\
\hline Men & $4.13 \pm 0.67$ & $6.38 \pm 0.77^{\text {㧊 }}$ & $9.85 \pm 1.59^{\ddagger \ddagger \S \S}$ \\
\hline Women & $3.08 \pm 0.66^{\star \star}$ & $4.77 \pm 0.97^{\star \star \ddagger \ddagger}$ & $7.94 \pm 1.22^{\star \star \neq \ddagger \S \S}$ \\
\hline \multicolumn{4}{|c|}{ Power $\left(k J \times s^{-1}\right)$} \\
\hline Men & $2.92 \pm 0.64$ & $1.99 \pm 0.33^{\ddagger \ddagger}$ & $1.30 \pm 0.21^{\ddagger \neq \S \S}$ \\
\hline Women & $1.96 \pm 0.41^{\star \star}$ & $1.41 \pm 0.32^{\star \star \ddagger \ddagger}$ & $1.01 \pm 0.16^{\star \star \neq \ddagger \S \S}$ \\
\hline
\end{tabular}

Significantly different from men at $p \leq 0.01^{* *}$ in 50,100 , and $200 \mathrm{~m}$.

Significantly different from $50 \mathrm{~m}$ at $p \leq 0.01^{\text {} \neq}$.

Significantly different from $100 \mathrm{~m}$ at $p \leq 0.01 \S \S$.

of $250 \mathrm{~m}$ at $50,55,60,70,80$, and $90 \%$ plus a single set at $100 \%$ of $200 \mathrm{~m}$ test, or until voluntary exhaustion (i.e., when swimmers were unable to follow the pacing or stop the exercise (Almeida et al., 2021); and (iii) 50, 100, and $200 \mathrm{~m}$ maximal trials (see Figure 1). The control of the swimming velocity during the incremental step test was provided by an underwater LED circuit (Pacer2 Swim ${ }^{\circledR}$, KulzerTEC, Aveiro, Portugal). At the end of each step, a passive rest (30 s) was performed for blood lactate sampling. All procedures were performed in a $25 \mathrm{~m}$ indoor pool and, to minimize the differences of prior exercise and the circadian rhythms effects, the same environmental conditions were applied ( $\sim 50$ of relative humidity, $\sim 28^{\circ} \mathrm{C}$ of water temperature, and $\pm 2 \mathrm{~h}$ of time of day). The tests were performed during the preparatory period of the training season, and all swimmers went through a familiarization process with the gas collection instruments in the week before the experiments.

Pulmonary gas exchange was analyzed breath-by-breath during and in the $420 \mathrm{~s}$ after the incremental step test and the 50,100, and $200 \mathrm{~m}$ maximal trials were analyzed using a portable gas analyzer ( $\mathrm{K} \mathrm{b}^{2}$, Cosmed, Rome, Italy) connected to the swimmer by a respiratory snorkel (newAquaTrainer ${ }^{\circledR}$, Cosmed, Rome, Italy; Baldari et al., 2013). The $\mathrm{K}_{4} \mathrm{~b}^{2}$ unit was calibrated before each test according to the manufacturer's instructions, and the snorkel was connected to the swimmer before each test for assessing the $\dot{\mathrm{VO}}_{2}$ baseline (e.g., last $30 \mathrm{~s}$ averaged values sampled with swimmer resting for $10 \mathrm{~min}$ seated on the pool wall). Blood samples $(25 \mu \mathrm{l})$ were collected before each test, during the intervals of the incremental step test, and at the 1st, 3rd, 5th, and 7th min after all tests for peak blood lactate concentration determination $\left(\left[\mathrm{La}^{-}\right]_{\text {peak }}\right)$ (YSI, 2300 STAT, Yellow Springs, $\mathrm{OH}$, United States).

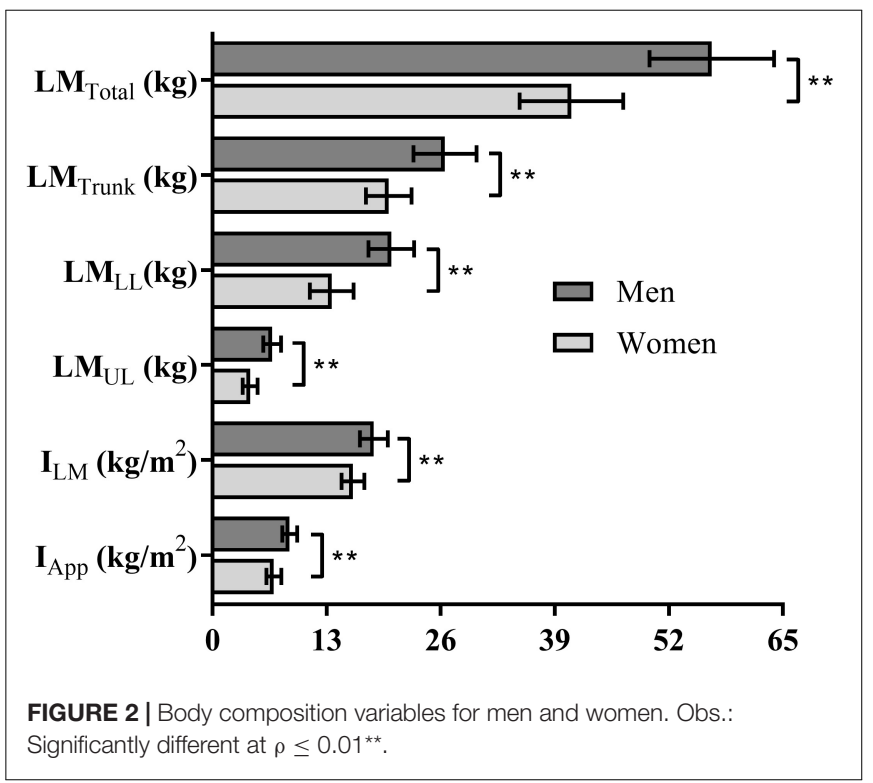

Dual-energy x-ray absorptiometry (DXA; Hologic ${ }^{\circledR}, \mathrm{QDR}$ Discovery $\mathrm{Wi}^{\circledR}$ ) was used for obtaining regional and wholebody composition, with the software Hologic APEX ${ }^{\circledR}$ displaying values for body mass, bone mass, body lean mass $\left(\mathrm{LM}_{\mathrm{Total}}\right)$, trunk lean mass $\left(\mathrm{LM}_{\text {Trunk }}\right)$, upper limb lean mass $\left(\mathrm{LM}_{U L}\right)$, lower limb lean mass $\left(\mathrm{LM}_{L L}\right)$, lean mass index $\left(\mathrm{I}_{L M}=\mathrm{LM} \times \mathrm{H}^{1 / 2}\right)$, and appendicular muscle index $\left(\mathrm{I}_{A p p}=\operatorname{LM}_{A p p} \times \mathrm{H}^{1 / 2}\right)$. The measurements for upper and lower limbs are the results from the sum of the left and right upper and lower limbs values, respectively, the trunk measurements corresponded to the central body region (from neck to pelvis), and the lean 
mass measurements result from fat free mass minus bone mineral content (Sala et al., 2007). The equipment was calibrated following the manufacturer's recommendations, and all the analysis were operated by an experienced technician. Participants wore light clothing and were positioned in the supine position on a flat table with the feet close together and the upper limbs placed parallel to the trunk.

The $\dot{\mathrm{VO}}_{2}$ data obtained during incremental step test were smoothed (3 s filter and $15 \mathrm{~s}$ moving mean) and peak $\dot{\mathrm{V}} \mathrm{O}_{2}\left(\dot{\mathrm{VO}}_{2 \text { peak }}\right)$ considered the highest value observed, while the velocity at the stage where the $\dot{\mathrm{V}} \mathrm{O}_{2 \text { peak }}$ was attained and was corresponded to the $\mathrm{vVO}_{2 \text { peak }}$, despite the swimmer being able to initiate another step and the $\mathrm{VO}_{2}$ rise was not larger than $\sim 2 \mathrm{ml} \times \min ^{-1} \times \mathrm{kg}^{-1}$ (Reis et al., 2012). From the performance of 50, 100, and $200 \mathrm{~m}$, the breath-bybreath $\dot{\mathrm{VO}}_{2}$ was continuously sampled during each trial with a recovery for $420 \mathrm{~s}$. The data were time aligned, followed by noise exclusion (coughing, sighing, and sneezing), which were defined as three standard-deviation from the local mean of five breaths and, finally, the data were interpolated second-by-second (Pessoa Filho et al., 2012). $\dot{V O}_{2}$ off-kinetics was adjusted by a biexponential equation according to Scheuermann et al. (2001) (Eq. 1):

$$
\begin{aligned}
V O_{2}(t)= & E E V O_{2}-A_{1} \text { off }\left\{1-e^{-\left[\left(t_{f}-T D_{1}\right) / \tau_{1}\right]}\right\}- \\
& A_{2 \text { off }}\left\{1-e^{-\left[\left(t_{f}-T D_{2}\right) / \tau 2\right]}\right\}
\end{aligned}
$$

where $\mathrm{EEVIO}_{2}$ is the end-exercise $\mathrm{V}_{2}$ (the last $15 \mathrm{~s}$ moving averaged value), representing the baseline at the very onset of the recovery phase. The physiologically relevant exponential $\mathrm{VO}_{2}$ response is the primary phase $\left(\mathrm{A}_{10 f f}\right)$ of the recovery curve and the amplitude of the second phase $\left(\mathrm{A}_{2 \text { off }}\right)$ corresponds to the slow component of $\dot{\mathrm{V}}_{2}$ recovery $\left(\mathrm{SCVO}_{2}\right)$. The time delay $\left(\mathrm{TD}_{1}\right.$ and $\mathrm{TD}_{2}$ ) and time constants $\left(\tau_{1}\right.$ and $\left.\tau_{2}\right)$ describe the onset and the velocity of $\mathrm{VO}_{2}$ recovery in each phase and $t_{f}$ is the total recovery time. The cardiodynamic phase at the beginning of the recovery was excluded by removing the first $15-20 \mathrm{~s}$ of $\mathrm{V}^{\mathrm{O}_{2}}$ response (Özyener et al., 2001).

During each swimming test, the aerobic energy demand $\left(\mathrm{E}_{\mathrm{Aer}}\right)$ was obtained from the net $\dot{\mathrm{V}}_{2}$ curve time integral (Eq. 2), and the anaerobic energy demand $\left(\mathrm{E}_{\mathrm{An}}\right)$, in $\mathrm{O}_{2}$ equivalents $\left(\mathrm{EqO}_{2}\right)$, was obtained by the phosphagen $\left(\mathrm{E}_{\mathrm{PCr}}\right)$ and glycolytic $\left(\mathrm{E}_{[\mathrm{La}-]}\right)$ components (Margaria et al., 1933; di Prampero and Ferretti, 1999). The $\mathrm{E}_{\mathrm{PCr}}$ was determined from the recovery phase fast component $\left(\mathrm{V}_{2 \text { Fast }}\right)$ using data from the off-kinetic primary phase considering the $\mathrm{VO}_{2}$ magnitude from the $\mathrm{TD}_{1}$ limited to the total recovery time (Stirling et al., 2005; Eq. 3). The amount of $9 \%$ corresponding to $\mathrm{O}_{2}$ body reserves was subtracted from $\dot{V}_{2 \text { Fast }}$ to strictly reflect the $\mathrm{E}_{\mathrm{PCr}}$ debt after exercise (Medbo et al., 1988; di Prampero and Ferretti, 1999;
Weber and Schneider, 2002). $\mathrm{E}_{[\mathrm{La}}-\mathrm{]}$ was determined according to Eq. 4 (di Prampero and Ferretti, 1999).

$$
\begin{gathered}
E_{\mathrm{Aer}}=\int_{t_{0}}^{t_{\text {Lim }}} \dot{V} \mathrm{O}_{2} \times \mathrm{d} t \\
\dot{V} \mathrm{O}_{2 \text { Fast }}=A_{1_{\text {Off }}} \times \tau_{1}\left\{1-\mathrm{e}^{\left[\left(t_{f}-T D_{1}\right) / \tau_{1}\right]}\right\}+ \\
A_{1_{\text {Off }}}\left\{\left(T D_{1}-t_{f}\right) \mathrm{e}^{\left[\left(t_{f}-T D_{1}\right) / \tau_{1}\right]}\right\} \\
E_{\left[\mathrm{La}^{-}\right]}=\left[\left(\beta \times \Delta\left[\mathrm{La}^{-1}\right] \times \mathrm{BM}\right)\right]
\end{gathered}
$$

where $\beta$ is the $\mathrm{O}_{2}$ equivalent for each $1.0 \mathrm{mmol} \times \mathrm{L}^{-1}$ $\left[\mathrm{La}^{-}\right]$of variation above the baseline value corresponding to $2.72 \mathrm{ml} \times \mathrm{kg}^{-1}$ in swimming, $\Delta\left[\mathrm{La}^{-}\right]$is the variation of the $\left[\mathrm{La}^{-}\right]$ above the resting value $\left(\Delta\left[\mathrm{La}^{-}\right]=\left[\mathrm{La}^{-}\right]_{\text {peak }}-\left[\mathrm{La}^{-}\right]_{\text {rest }}\right)$, and BM is the whole-body mass in $\mathrm{kg}$.

The estimated absolute values of each of the above-referred energetic components provide total energetic demand $\left(\mathrm{E}_{\text {Total }}\right)$ and were converted into J, assuming an energy equivalent of 20.9 $\mathrm{kJ} \times \mathrm{LO}_{2}{ }^{-1}$. Subsequently, this energy demand was normalized by the performance time, providing a value in $\mathrm{kJ} \times \mathrm{s}^{-1}$, i.e., the absolute power equivalent. Finally, this power unit was rated by the swimming velocity for each swimming distance providing the $\mathrm{C}\left(\mathrm{kJ} \times \mathrm{m}^{-1}\right)$. The value of the anaerobic $\mathrm{C}\left(\mathrm{C}_{\mathrm{An}}\right)$ was determined by the sum of $\mathrm{C}_{\mathrm{PCr}}$ and $\mathrm{C}_{[\mathrm{La}}-{ }_{]}$, and the total cost $\left(\mathrm{C}_{\text {Total }}\right)$ was obtained from the sum of the $\mathrm{C}_{\mathrm{An}}$ and aerobic $\mathrm{C}\left(\mathrm{C}_{\text {Aer }}\right)$.

Normality of the data was checked with Shapiro-Wilk test $(n<50)$, the sphericity by the Mauchly test, and using the Greenhouse-Geisser correction when violated. Independent $t$-student test analyzed the effect of sex on body composition variables and on swimming velocity, time performance, $\left[\mathrm{La}^{-}\right]_{\text {peak }}$, and estimated absolute values in $\mathrm{EqO}_{2}, \mathrm{P}$, and $\mathrm{E}_{\text {Total }}$ for each of the studied test distances. The differences in energetics and $\mathrm{C}$ values between sexes (men vs. women) by distances (i.e., 50, 100, and $200 \mathrm{~m}$ ) and for each distance by sex were tested by the two-way ANOVA, with Bonferroni as post hoc test for pairwise comparison. The effect size for the $t$-student test was calculated using Hedges' $g$ and interpreted as follows: $<0.19$ (insignificant), 0.20-0.49 (small), 0.50-0.79 (moderate), 0.801.29 (large), and $>1.30$ (very large) (Rosenthal, 1996). For ANOVA, the partial square eta $\left(\eta^{2}\right)$ was used and interpreted as follows: 0.0099 (small), 0.0588 (medium), and 0.1379 (large; Cohen, 1988).

The relationships between $\mathrm{C}$ and body composition variables were assessed by Pearson's coefficient and classified as follows: 0.00-0.29 (small), 0.30-0.49 (low), 0.50-0.69 (moderate), 0.700.89 (high), and 0.90-1.00 (very high; Mukaka, 2012). The regression coefficient that was adjusted to the sample $\left(R^{2}{ }_{a d j}\right)$ analyzed the similarity of variance between $\mathrm{C}$ and body composition variables during each 50,100, and $200 \mathrm{~m}$ distance and was considered as $<0.04$ (trivial), 0.04-0.24 (small), $0.25-$ 0.63 (medium), and $>0.64$ (strong; Ferguson, 2009). Pearson and 

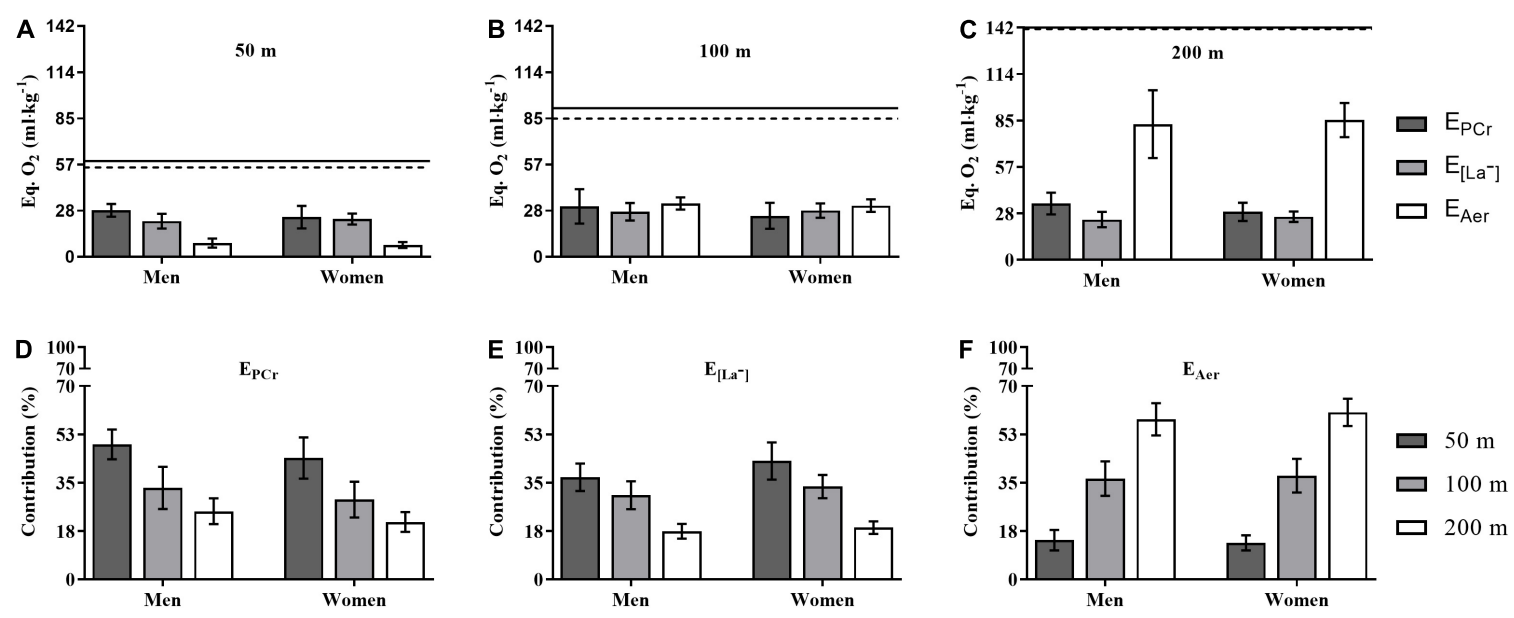

FIGURE 3 | The energetic demand (A-C) contribution (D-F) to the performance in 50, 100, and 200 m for men and women. Obs.: Horizontal continuous and traced lines at the top of Panels $(\mathbf{A}-\mathbf{C})$ refer to $E_{T o t a l}$ for men and women, respectively. The acronyms $E_{P C r}$, $E_{[L a}-$ ], and $E_{A e r}$ represent the phosphagenic, glycolytic, and aerobic components of $\mathrm{E}_{\text {Total. }}$. See text for statistical analysis.

regression analysis were controlled for the sex-specific variance of the values. The sample power for the coefficient of correlation, considering the sample size, was the corresponding value of $Z \alpha=1.96$ for a security index of $\alpha=0.05$. The level of significance was set at $\rho \leq 0.05$ for all analysis, with all statistical analyzes performed with the Statistical Package for the Social Sciences (SPSS, version 26.0, Chicago, IL, United States).

\section{RESULTS}

The $\dot{\mathrm{V}} \mathrm{O}_{2 \text { peak }}$ values associated to the incremental test was $4.05 \pm 0.46$ and $3.09 \pm 0.36 \mathrm{LO}_{2}$, and $\mathrm{vVO}_{2}$ peak corresponded to $1.30 \pm 0.07$ and $1.20 \pm 0.06 \mathrm{~m} \times \mathrm{s}^{-1}$, respectively, for men and women. During the $\mathrm{v} 50 \mathrm{~m}, \mathrm{v} 100 \mathrm{~m}$, and $\mathrm{v} 200 \mathrm{~m}$, the performances corresponded to $129.8 \pm 13.7,114.8 \pm 9.0$, and $97.4 \pm 7.9 \%$ of $\mathrm{vVO}_{2 \text { peak }}$ for men and $126.7 \pm 8.6,117.7 \pm 6.9$, and $101.9 \pm 5.7 \%$ of $\mathrm{vVO}_{2 \text { peak }}$ for women with no differences between sexes for each distance (all at $\rho>0.05$ ). The data related to performances and physiological responses are shown in Table $\mathbf{1 .}$ Swimming velocity and $p$ were higher for short compared to long swimming distances (i.e., $50>100>200 \mathrm{~m}$ ), while total energy measurements in $\mathrm{EqO}_{2}$ increased with swimming distance (i.e., $50<100<200 \mathrm{~m}$ ). Males demanded higher $\mathrm{EqO}_{2}$ and $p$ than female swimmers for the 50,100 , and $200 \mathrm{~m}$, but the swimming velocity differed only during 50 and $100 \mathrm{~m}$ swimming bouts. Figure 2 highlights the differences between sexes regarding body composition variables. The comparisons between sexes for $\mathrm{LM}_{\text {Total, }} \mathrm{LM}_{\text {Trunk }}, \mathrm{LM}_{L L}, \mathrm{LM}_{U L}, \mathrm{I}_{L M}$, and $\mathrm{I}_{A p p}$ indicated higher values for men than women (all at $\rho<0.01$ ), with the effect size " $g$ " ranging from 1.43 to 2.60 and, therefore, were all considered very large.

The $\mathrm{E}_{\text {Total }}$ demand for men and women during 50 $\left(58.8 \pm 8.4\right.$ vs. $\left.54.9 \pm 8.2 \mathrm{ml} \times \mathrm{kg}^{-1}\right), 100(91.5 \pm 14.2$ vs. $\left.85.0 \pm 12.2 \mathrm{ml} \times \mathrm{kg}^{-1}\right)$, and $200 \mathrm{~m}(141.9 \pm 24.6$ vs. $\left.141.0 \pm 10.4 \mathrm{ml} \times \mathrm{kg}^{-1}\right)$ did not differ $(\rho=0.24,0.23$, and
0.91) between sexes for each distance. Figure 3 depicts the energetics during the performances of the 50,100, and $200 \mathrm{~m}$ with regards to the demands (Panels $\mathrm{A}-\mathrm{C}$, in $\mathrm{EqO}_{2}$ per $\mathrm{BM}$ ) and contributions [Panels D-F, in relative terms (\%)] attained by the energetics components $\left(\mathrm{E}_{\mathrm{PCr}}, \mathrm{E}_{[\mathrm{La}-]}\right.$, and $\left.\mathrm{E}_{\mathrm{Aer}}\right)$. The $\mathrm{E}_{\mathrm{PCr}}$ contribution was higher for men than women only for the $200 \mathrm{~m}$ $\left(\rho=0.04, \eta^{2} \mathrm{p}=0.247\right)$, with no differences for the $50(\rho=0.75)$ and $100 \mathrm{~m}(\rho=0.13)$ distances, while the $\left.\mathrm{E}_{[\mathrm{La}}-\right]$ and $\mathrm{E}_{\mathrm{Aer}}$ components showed no differences between sexes for the 50 ( $\rho=0.40$ and 0.22$), 100(\rho=0.73$ and 0.37$)$, and $200 \mathrm{~m}(\rho=0.30$ and 0.70$)$ distances. The contributions of $\mathrm{E}_{\mathrm{PCr}}, \mathrm{E}_{[\mathrm{La}}-{ }_{]}$, and $\mathrm{E}_{\mathrm{Aer}}$ components to the $\mathrm{E}_{\text {Total }}$ demand in the 50,100, and $200 \mathrm{~m}$ differed between all distances for men and women at $\rho<0.01$ level, i.e., $\% \mathrm{E}_{\mathrm{PCr}} 50>100>200 \mathrm{~m}\left(\eta^{2} \mathrm{p}=0.815\right) ; \% \mathrm{E}_{[\mathrm{La}}-$ ] $50>100>200 \mathrm{~m}\left(\eta^{2} \mathrm{p}=0.890\right)$; and $\% \mathrm{E}_{\text {Aer }} 50<100<200 \mathrm{~m}$ $\left(\eta^{2} \mathrm{p}=0.954\right)$, whatever the sex. Moreover, men had higher $\% \mathrm{EPCr}_{\mathrm{PC}}$ in the $200 \mathrm{~m}$ than women $(\rho=0.03)$, while women had higher $\left.\% \mathrm{E}_{[L a}-\right]$ in the $50 \mathrm{~m}$ than men $(\rho=0.02)$, with no other differences.

For the performances in the 50,100, and $200 \mathrm{~m}$ tests, the values obtained for $C_{A n}, C_{A e r}$, and $C_{\text {Total }}$ are presented in Figure 4. The Panels A-C (Figure 2) demonstrate the sex-effect on $\mathrm{C}_{\mathrm{An}}, \mathrm{C}_{\mathrm{Aer}}$, and $\mathrm{C}_{\text {Total }}$, with higher values for men than women in the 50,100, and $200 \mathrm{~m}$ tests $\left(\rho<0.01\right.$, and $\eta^{2} p=0.456,=0.487$, and $\left.=0.519\right)$. Also, the reduction of $\mathrm{C}_{\mathrm{An}}$ and $\mathrm{C}_{\text {Total }}$ values with the increase of the swimming distance was observed for both sexes (Panels $\mathrm{A}$ and C), i.e., $\mathrm{C}_{\mathrm{An}}$ and $\mathrm{C}_{\text {Total }}$ in $50>100>200 \mathrm{~m}(\rho<0.01$, and $\eta_{p}^{2}=0.919$ and $\left.=0.778\right)$. However, the $C_{\text {Aer values were higher }}$ with the increase of the swimming distance for both sexes (Panel B), i.e., $\mathrm{C}_{\text {Aer }}$ in $50<100<200 \mathrm{~m}\left(\rho<0.01\right.$, and $\left.\eta_{p}^{2}=0.838\right)$. When expressed per unit of body mass (i.e., $\mathrm{J} \times \mathrm{kg}^{-1} \times \mathrm{m}^{-1}$ ), the $\mathrm{C}_{\text {Total }}$ values did not differ for men vs. women in 50 (24.6 vs. 23.0, $\rho=0.24), 100$ (19.1 vs. 17.8, $\rho=0.22$ ), and $200 \mathrm{~m}$ (14.8 vs. 14.7, $\rho=0.91)$.

Table 2 shows the Pearson's coefficients for the correlations of whole-body and regional lean mass variables with the 


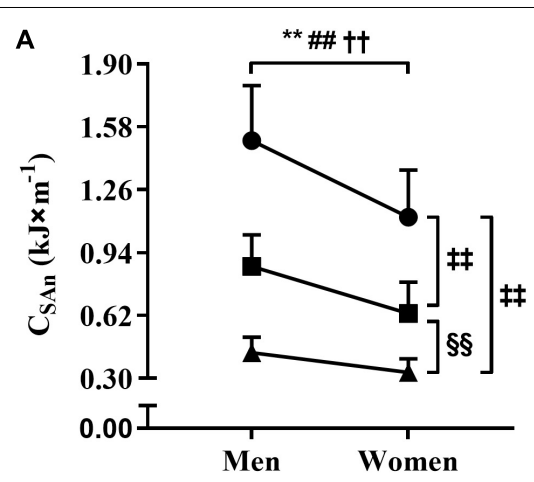

B
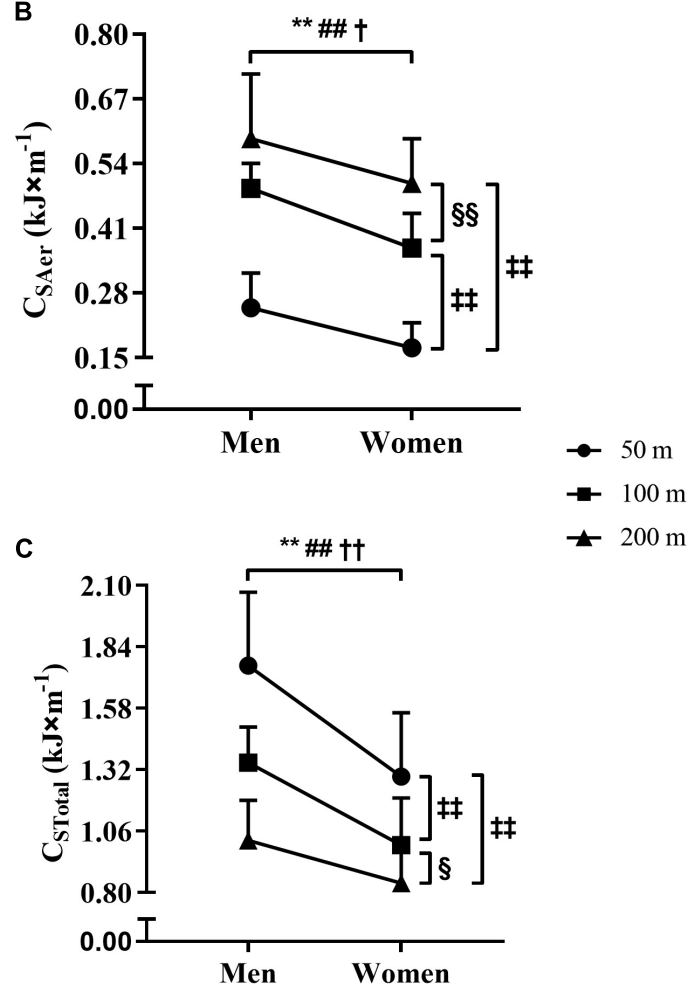

FIGURE 4 | The comparisons of $\mathrm{C}_{\mathrm{An}}, \mathrm{C}_{\mathrm{Aer}}$, and $\mathrm{C}_{\text {Total }}$ values (A-C) between the sexes and distances. Obs.: The acronyms $\mathrm{C}_{\mathrm{An}}, \mathrm{C}_{\mathrm{Aer}}$, and $\mathrm{C}_{\text {Total }}$ represent the anaerobic, aerobic, and total costs. Significantly different from men at $\rho \leq 0.05^{\dagger}$ in $200 \mathrm{~m}$, and at $\rho \leq 0.01$ in $50^{\star \star}, 100^{\# \#}$, and $200 \mathrm{~m}^{\dagger \dagger}$.

Significantly different from $50 \mathrm{~m}$ at $\rho \leq 0.01^{\sharp \ddagger}$. Significantly different from 100 $\mathrm{m}$ at $\rho \leq 0.05 \S$ and $\leq 0.01 \S \S$.

measurements of $C_{A n}, C_{\text {Aer }}$, and $C_{\text {Total }}$ in 50, 100, and $200 \mathrm{~m}$. The correlations were considered significant, classified as moderate or high, and attaining SP $\geq 95 \%$ for all analysis, with exception to the $\mathrm{LM}_{U L}, \mathrm{I}_{L M}$, and $\mathrm{I}_{A p p}$ with $\mathrm{C}_{\text {Total }}$ in the $200 \mathrm{~m}$, which were low and $\mathrm{SP}<80 \%$. The variables $\mathrm{LM}_{\text {Trunk }}, \mathrm{LM}_{U L}$, and $\mathrm{LM}_{L L}$ showed medium to strong influence on $\mathrm{C}_{\mathrm{An}}, \mathrm{C}_{\mathrm{Aer}}$, and $\mathrm{C}_{\text {Total }}$ values in the 50, 100, and $200 \mathrm{~m}$ (Figure 5, Panels A-I), with $\mathrm{LM}_{\text {Trunk }}$ and $\mathrm{LM}_{U L}$ attaining high rates to explain the $\mathrm{C}_{\mathrm{An}}$ values during these distances (Panels A-C), and $\mathrm{LM}_{L L}$ as the variable explaining the

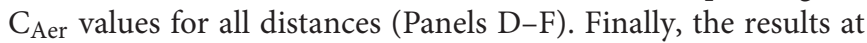

Panels G-I highlight the rates of 72, 61, and 60\% for the variables $\mathrm{LM}_{\text {Trunk }}, \mathrm{LM}_{U L}$, and $\mathrm{LM}_{L L}$, explaining $\mathrm{C}_{\text {Total }}$ values in 50,100 , and $200 \mathrm{~m}$, respectively.

\section{DISCUSSION}

This study addressed the $\mathrm{C}$ during short and middle distances performances in swimming, finding a sex-specific response regarding the energetics contribution to the performances, to $\mathrm{C}$ during each swimming distance, and to the role of regional lean mass on $\mathrm{C}$ values. The findings indicated no differences between sexes for the $\mathrm{E}_{\text {Total }}$ and for the components $\mathrm{E}_{\mathrm{PCr}}, \mathrm{E}_{[\mathrm{La}}-\mathrm{]}$, and $\mathrm{E}_{\text {Aer }}$, suggesting similar capacity between young men and women to meet the energy requirements per unit of body mass in a front crawl. However, the $\mathrm{C}_{\text {Total }}$ was higher in men than women for all swimming distances performed, despite how both sexes presented similar $\mathrm{C}$ components regarding the reliance on $\mathrm{C}_{A n a}$ and $\mathrm{C}_{\mathrm{Aer}}$ expenditure, respectively, during short distances (50 and $100 \mathrm{~m}$ ) and middle distances $(200 \mathrm{~m})$. For the current study, these differences in $\mathrm{C}_{\mathrm{An}}, \mathrm{C}_{\mathrm{Aer}}$, and $\mathrm{C}_{\text {Total }}$ can be attributed to the increased production of metabolic power in men, which was observed to relate to lean mass in the trunk and upper and lower limbs.

The similarities for $\mathrm{E}_{\mathrm{PCr}}, \mathrm{E}_{[\mathrm{La}}-\mathrm{]}$, and $\mathrm{E}_{\mathrm{Aer}}$ in the 50, 100, and $200 \mathrm{~m}$ (with $\mathrm{E}_{\mathrm{PCr}}$ at the $200 \mathrm{~m}$ being the only exception) support the evidence that fast-energy pathways (i.e., phosphagens and glycolysis), level of activation, and contribution, while the oxidative supply is rising from short to middle distances performances, have no constraints related to sex-specific energy metabolism. In addition, similarities were also noted to the interplay (\% of contribution) between $\mathrm{E}_{\mathrm{PCr}}, \mathrm{E}_{[\mathrm{La}}-\mathrm{]}$, and $\mathrm{E}_{\mathrm{Aer}}$ as trial time increases from the 50 to $200 \mathrm{~m}$, evidencing that sex has no influence on given metabolism requirements neither on the balance between the metabolism components as the demand changes according to the swimming intensity and duration over the distances.

These findings are aligned with the evidence toward similarities in energetics rely on fiber type distribution in biceps brachialis and vastus lateralis, with no differences between young men and women, and on the reports relating fiber firing to exercise intensity as sex-independent (Esbjörnsson et al., 1993; Miller et al., 1993; Hunter, 2016). In addition, other reports evidencing larger fiber areas (I, IIa, and IIb) of the biceps brachialis and vastus lateralis in men than women (Esbjörnsson et al., 1993; Miller et al., 1993) probably account for the differences in total muscle PCr content between sexes (Esbjörnsson et al., 1993; Esbjörnsson-Liljedahl et al., 1999). Therefore, the PCr content might explain the small differences between sexes observed in the current study and account for the higher reliance on $\mathrm{E}_{\mathrm{PCr}}$ in men compared to women as the distance increases from 50 to $200 \mathrm{~m}$, and for the women reliance on larger $\mathrm{E}_{[\mathrm{La}-\mathrm{l}}$ than men during the performance of short distance, i.e., $50 \mathrm{~m}$.

However, the finding in which no differences between men and women, regarding anaerobic glycolytic contribution, is not in agreement with the well-reported reduced glycolytic activity 
TABLE 2 | Relationship between body composition variables and values of $C_{A n}, C_{\text {Aer }}$, and $C_{\text {Total }}$ for the 50, 100, and $200 \mathrm{~m}$.

\begin{tabular}{|c|c|c|c|c|c|c|c|}
\hline & & $\mathbf{L M}_{\text {Total }}$ & $\mathbf{L M}_{\text {Trunk }}$ & $\mathbf{L M}_{\mathrm{LL}}$ & $\mathrm{LM}_{\mathrm{UL}}$ & $I_{\text {LM }}$ & $I_{\text {App }}$ \\
\hline \multirow[t]{6}{*}{$\mathrm{C}_{\mathrm{An}}$} & $50 \mathrm{~m}$ & $0.85^{\star \star}$ & $0.86^{\star \star}$ & $0.82^{\star *}$ & $0.81^{\star \star}$ & $0.76^{\star \star}$ & $0.74^{\star \star}$ \\
\hline & & (100\%) & (100\%) & (100\%) & (100\%) & (100\%) & (99\%) \\
\hline & $100 \mathrm{~m}$ & $0.68^{\star \star}$ & $0.68^{\star \star}$ & $0.64^{\star \star}$ & $0.70^{\star \star}$ & $0.65^{\star \star}$ & $0.64^{\star \star}$ \\
\hline & & $(97 \%)$ & (97\%) & (95\%) & (98\%) & (95\%) & (95\%) \\
\hline & $200 \mathrm{~m}$ & $0.85^{\star \star}$ & $0.86^{\star \star}$ & $0.83^{\star \star}$ & $0.82^{\star \star}$ & $0.77^{\star \star}$ & $0.75^{\star \star}$ \\
\hline & & (100\%) & (100\%) & (100\%) & (100\%) & (100\%) & (100\%) \\
\hline \multirow[t]{6}{*}{$\mathrm{C}_{\text {Aer }}$} & $50 \mathrm{~m}$ & $0.56^{\star \star}$ & $0.54^{\star \star}$ & $0.56^{\star \star}$ & $0.57^{\star \star}$ & $0.47^{\star}$ & $0.52^{\star *}$ \\
\hline & & (84\%) & (82\%) & (84\%) & (86\%) & (67\%) & $(76 \%)$ \\
\hline & $100 \mathrm{~m}$ & $0.75^{\star \star}$ & $0.71^{\star \star}$ & $0.73^{\star *}$ & $0.73^{\star \star}$ & $0.65^{\star \star}$ & $0.71^{\star *}$ \\
\hline & & (100\%) & (99\%) & (100\%) & (99\%) & (95\%) & (99\%) \\
\hline & $200 \mathrm{~m}$ & $0.56^{\star \star}$ & $0.54^{\star \star}$ & $0.59^{\star *}$ & $0.46^{\star}$ & $0.41^{*}$ & $0.45^{\star}$ \\
\hline & & (84\%) & (82\%) & (88\%) & (66\%) & $(53 \%)$ & $(63 \%)$ \\
\hline \multirow[t]{6}{*}{$\mathrm{C}_{\text {Total }}$} & $50 \mathrm{~m}$ & $0.85^{\star \star}$ & $0.86^{\star \star}$ & $0.83^{\star \star}$ & $0.82^{\star \star}$ & $0.75^{\star \star}$ & $0.75^{\star *}$ \\
\hline & & (100\%) & (100\%) & (100\%) & (100\%) & (100\%) & (100\%) \\
\hline & $100 \mathrm{~m}$ & $0.78^{\star \star}$ & $0.77^{\star \star}$ & $0.76^{\star \star}$ & $0.79^{\star \star}$ & $0.73^{\star \star}$ & $0.74^{\star *}$ \\
\hline & & (100\%) & $(100 \%)$ & (100\%) & (100\%) & (99\%) & (99\%) \\
\hline & $200 \mathrm{~m}$ & $0.78^{\star \star}$ & $0.78^{\star \star}$ & $0.79^{\star \star}$ & $0.71^{* *}$ & $0.65^{\star \star}$ & $0.66^{\star \star}$ \\
\hline & & (100\%) & (100\%) & (100\%) & (98\%) & (95\%) & (96\%) \\
\hline
\end{tabular}

Obs.: Data are showing the coefficient ( $r$ ) and sample power in percentage.

Significantly different at $\rho \leq 0.05^{\star}$ and $\leq 0.01^{\star *}$.

$L M_{\text {Total, }} L M_{\text {Trunk, }}$ LMLL, and LM $M_{U L}$ are lean mass in whole-body, trunk and lower and upper limbs, and $I_{L M}$ and $I_{\text {App }}$ are lean mass index and appendicular lean mass index.

for women when compared to men during Wingate and MAOD tests in cycling and running (Esbjörnsson et al., 1993; GratasDelamarche et al., 1994; Naughton et al., 1997; Hill and Vingren, 2011). These studies attributed the differences upon glycolytic demand to the higher absolute exercise intensity reached by men (i.e., peak power) since no significant differences between sexes in power (Maud and Shultz, 1986; Nindl et al., 1995; Hegge et al., 2015) or anaerobic demand (Weber and Schneider, 2002) were found when whole-body and regional mass or lean mass were considered.

In addition, the $\left[\mathrm{La}^{-}\right]_{\text {peak }}$ values for the current study are aligned with the values reported for the 50,100, and $200 \mathrm{~m}$ maximal swimming performances (Chatard et al., 1988; Troup et al., 1992; Capelli et al., 1998) and, therefore, the acidosis level is compatible to the other results exploring the energetics requirements during short and middle distances swimming performance. Furthermore, the observed similarities between men vs. women in $\left[\mathrm{La}^{-}\right]_{\text {peak }}$ and $\mathrm{E}_{[\mathrm{La}}-\mathrm{]}$ responses cannot be attributed to the trial differences in $\% v \mathrm{VO}_{2 \text { peak }}$ and duration during each performance since these parameters were not significantly different between sexes. The only exception was the duration of $50 \mathrm{~m}$, which was smaller in men than women. However, the differences seem to not be large enough to modify glycolytic contribution according to sex-specific performances.

The lack of differences between sexes was also observed for $\mathrm{E}_{\text {Aer }}$ responses in 50, 100, and $200 \mathrm{~m}$, which was an expected result considering the limited capacity to uptake and deliver oxygen to the working muscles at exercise rates higher than or close to $\dot{\mathrm{VO}}_{2 \text { peak }}$ for women is associated to the body size differences to men and, therefore, relating energetics to a scaling issue (Weber and Schneider, 2002). Indeed, the absolute differences in cardiac, circulatory, and respiratory determinants of $\mathrm{O}_{2}$ availability to muscle while exercising near or at $100 \%$ $\dot{\mathrm{V}} \mathrm{O}_{2 \text { peak }}$ are not significant when comparing sexes per unit of lean mass (Peltonen et al., 2013), which are further supported to the evidence that fiber type I functions and distribution, pulmonary diffusive capacity, blood volume, and hemoglobin content are not different when comparing between sexes accounting to the effect of body size or lean mass (Esbjörnsson-Liljedahl et al., 1999; Russ et al., 2005; Haizlip et al., 2015; Bouwsema et al., 2017; Koons et al., 2019).

Analogous to the evidence of "size" effect on energetics between sexes (Chatard et al., 1991), the results from the current study also observed higher absolute energy demand in $\mathrm{EqO}_{2}$ for men compared to women in the 50, 100, and $200 \mathrm{~m}$ tests, either considering the total (i.e., $\mathrm{E}_{\text {Total }}$ ) or the components of the energetics (i.e., $\mathrm{E}_{\mathrm{PCr}}, \mathrm{E}_{[\mathrm{La}}-\mathrm{]}$ and $\mathrm{E}_{\mathrm{Aer}}$ ). These results remain unchanged even when considering the performance variable time or velocity to normalize energy demand, giving important insights into the relevance of body morphology for the sexspecific energetics response per unit of time or distance while swimming at high intensity rates. The remarkable finding is the predominance of anaerobic energy releasing per unit of distance in the 50 and $100 \mathrm{~m}$, whereas aerobic energy predominated along the $200 \mathrm{~m}$. Furthermore, aerobic and anaerobic C differed between sexes, with lean mass in the trunk and upper and lower limbs explaining $60-73 \%$ of $\mathrm{C}_{\text {Total }}$ for $50-200 \mathrm{~m}$.

In swimming, the energy contribution from phosphagen, glycolytic, and aerobic components during 50, 100, and $200 \mathrm{~m}$ has been reported to differ between sexes only in $200 \mathrm{~m}$ and with regards the phosphagen (men $>$ women) and glycolytic (men < women) contributions (Almeida et al., 2020). When 


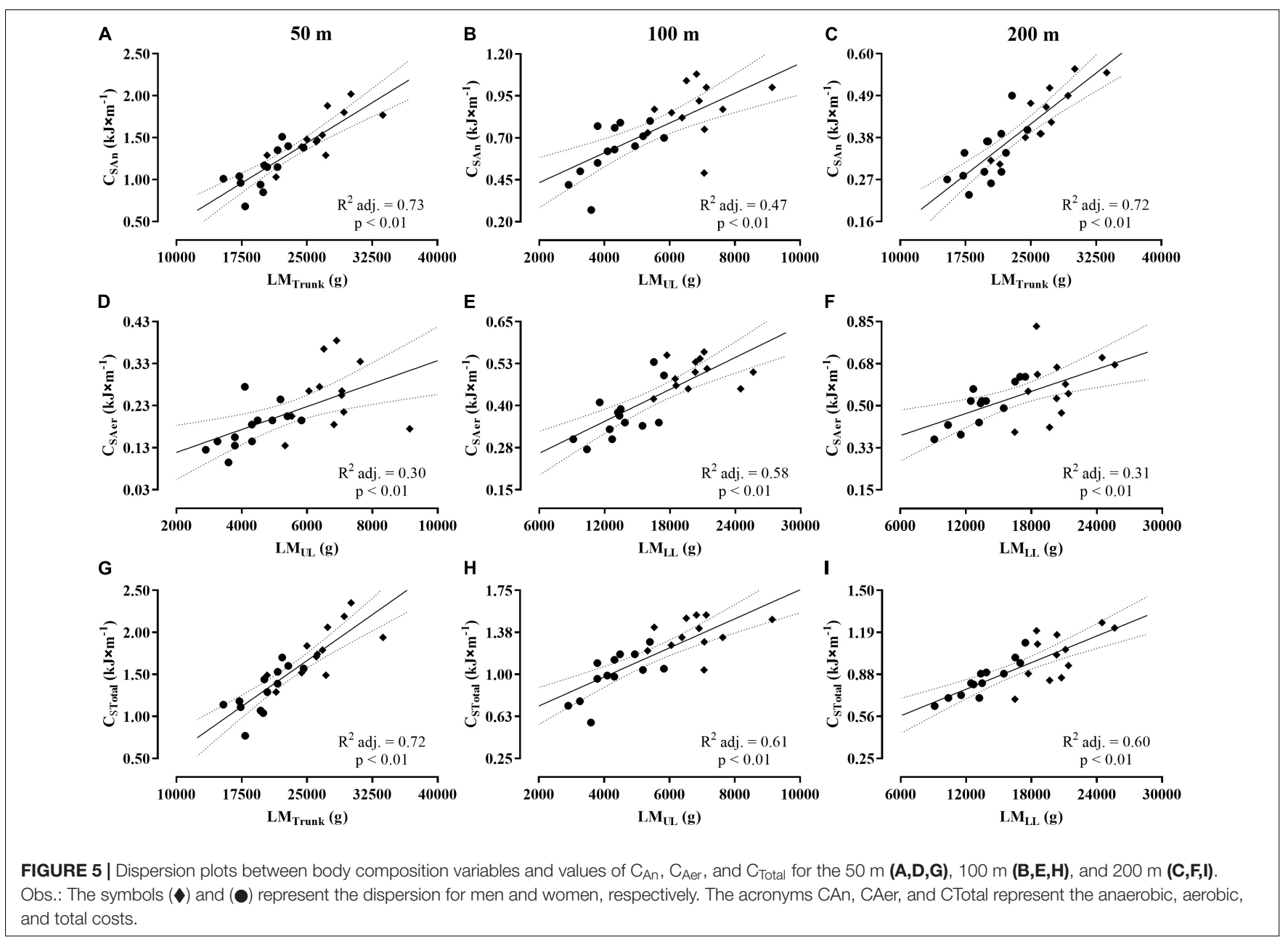

comparing the current data from the energy released with the aforementioned reports, there are slight differences with regards to anaerobic energetics, which are probably due to the methodological assumptions for the estimation of phosphagen and glycolytic components (i.e., the subtracted amount of hemoglobin $\mathrm{O}_{2}$ content and the stoichiometric coefficient for blood lactate net accumulation - Medbo et al., 1988; di Prampero and Ferretti, 1999) since swimmers are similar with regards to age group, conditioning index $\left(\mathrm{V}_{2 \text { peak }}\right.$ and $\left.\mathrm{v} \dot{\mathrm{V}} \mathrm{O}_{2 \text { peak }}\right)$, and performance pacing $\left(\mathrm{v}\right.$ and $\left.\% \mathrm{vVO} \mathrm{O}_{2 \text { peak }}\right)$. However, the differences between the studies are also large for aerobic contribution, which just reinforce the concerns on the data processing strategies influence on $\mathrm{VO}_{2}$ analysis (Robergs et al., 2010). However, the interpretation from Almeida et al. (2020) that energetics during short and middle distances performance did not differ between sexes per unit of body mass is aligned with the current results.

Indeed, the reports for aerobic and anaerobic percentage of contribution to total energy released by elite male swimmers in $50(\sim 15 / 85 \%), 100(\sim 33 / 77 \%)$, and 200 yards $(\sim 62 / 38 \%)$ (Capelli et al., 1998) are quite aligned to the current findings and therefore supports the reliance on anaerobic sources during performances around $60 \mathrm{~s}$, which has already been demonstrated for swimming (Capelli et al., 1998; Ogita et al., 2003) and cycling exercise (Bangsbo et al., 1990; Spencer and Gastin, 2001). The current results indicated a larger phosphagen than glycolytic contribution for the anaerobic releasing during 50 and $200 \mathrm{~m}$ in men, and similar contributions for these two components in women during 50,100 , and $200 \mathrm{~m}$, which are not aligned to previous reports. In fact, highest glycolytic reliance during short and middle distances performances have been observed in elite male swimmers [i.e.: $\mathrm{E}_{\mathrm{PCr}} / \mathrm{E}_{[\mathrm{La}}-$ ] $(\%) \sim 26 / 54,19 / 43,13 / 24$ in 50, 100 and 200 yards, Capelli et al., 1998; and $\mathrm{E}_{\mathrm{PCr}} / \mathrm{E}_{[L a}-$ ] (\%) $\sim 11 / 15$ in $200 \mathrm{~m}$, Sousa et al., 2013] and for junior and senior male swimmers [i.e., $\mathrm{E}_{\mathrm{PCr}} / \mathrm{E}_{[L a}-$ ] (\%) 20/27 and 18/37 in 100 m, Hellard et al., 2018], but exceptionally, Figueiredo et al. (2011) reported $\mathrm{E}_{\mathrm{PCr}} / \mathrm{E}_{[\mathrm{La}}$ - ] (\%) 20/14\% in $200 \mathrm{~m}$, which is close to the proportionality in the current study.

The aforementioned estimates of $\mathrm{E}_{\mathrm{PCr}}$, supposing a maximal depletion of PCr store (i.e., $18.5 \mathrm{mmol} / \mathrm{kg}$ of wet muscle at $23.4 \mathrm{~s}$ time constant for substrate splitting), have been suggested as reasonable (Capelli et al., 1998; Hellard et al., 2018) and expected to give similar results when compared to the analyzes of the fast component of $\dot{\mathrm{VO}}_{2}$ recovery curve (at least for the $200 \mathrm{~m}$ swimming performance; Sousa et al., 2013). However, in the current study, the values observed for the time constant of the $\dot{\mathrm{V}} \mathrm{O}_{2}$ recovery fast component ranged from 44 to $46 \mathrm{~s}$ for 50,100 , 
and $200 \mathrm{~m}$, which are in the range reported for severe exercise in cycling (35 $\pm 11 \mathrm{~s})$, high intensity lower limbs extension (51 \pm 6 s) (Özyener et al., 2001; Rossiter et al., 2002), and short distance swimming trial (Almeida et al., 2020) but diverge with that reported for $200 \mathrm{~m}$ in swimming (27 $\pm 5 \mathrm{~s}$, Sousa et al., 2013). Despite the differences of parameters selection (i.e., $\mathrm{EEVO}_{2}$ vs. $\dot{\mathrm{VO}}_{2 \text { baseline }}$ ) for the equation model that can account for the differences of the time constant response, the evidence of similarities or discrepancies between methods for phosphagen component estimation needed to be further investigated.

Nevertheless, considering that the release of $\sim 3.33, \sim 2.72$, and $\sim 1.94 \mathrm{~kW}$ in elite male college swimmers during short and middle distances performances at $\sim 139, \sim 123$, and $\sim 114 \%$ $\mathrm{vV}_{2 \max }$ (Capelli et al., 1998), and that the maximal anaerobic supply during high-intensity performances can reach 1,452 $\mathrm{J} \times \mathrm{kg}^{-1}$ (or $\left.\sim 69.5 \mathrm{ml} \times \mathrm{kg}^{-1}\right)$ in well-trained swimmers (Toussaint and Hollander, 1994), we suppose that the swimmers in the current study are still in the development training stage therefore requiring metabolic power output and anaerobic capacity improvements. Despite how the women have shown lower values, the average anaerobic release (i.e., $\mathrm{E}_{\mathrm{PCr}}+\mathrm{E}_{[\mathrm{La}}-$ ]) reached the highest values during the 100 and $200 \mathrm{~m}$ (e.g., $\sim 57 \mathrm{ml} \times \mathrm{kg}^{-1}$ ) which is lower than values for the $200 \mathrm{~m}\left(\sim 68 \mathrm{ml} \times \mathrm{kg}^{-1}\right)$ reported in international level male swimmers (Fernandes et al., 2006), corroborating the range for improvements in the aforementioned variables for young swimmers. However, the current values are also revealed to be higher than anaerobic release during $100 \mathrm{~m}$ (e.g., $\sim 48$ and $54 \mathrm{ml} \times \mathrm{kg}^{-1}$ ) as reported for male swimmers with 18-22 years old and low to high FINA points (Hellard et al., 2018), and higher than the estimated anaerobic capacity (e.g., $\sim 50-52 \mathrm{ml} \times \mathrm{kg}^{-1}$ ) for college swimmers (Ogita et al., 1996, 2003; Capelli et al., 1998).

From these comparisons, there is considerable support to consider no sex-constraints among young swimmers to reach the expecting anaerobic conditioning to compete at a high level despite the transference for elite performance being limited to the fact that current swimmers are well-trained but not toplevel athletes. However, the energy releasing sources do not seem to be the only determinant to the performance level during short and middle distances (Figueiredo et al., 2013; Ribeiro et al., 2017; Zacca et al., 2020), although the variables power and cost have been considered determinants of swimming performance, exercise tolerance, total energy requirement, and aerobic/anaerobic metabolism balance during high-intensity bouts (Toussaint, 1990; Chatard et al., 1991; Fernandes et al., 2006; di Prampero et al., 2008).

For example, as swimming velocity increases, the metabolic power should raise proportionality to afford mechanical adjustments with no technical impairments (i.e., accommodating higher stroke rate with minimal disturbance in stroke length), allowing to differentiate swimmers according to the conditioning and technical levels (Toussaint, 1990; Wakayoshi et al., 1995; Ribeiro et al., 2017). This explains the lower race pace, energy power, and cost when comparing men from the current study with college male swimmers performing short and middle distances, or even the economical pacing of these later swimmers when compared to the ones from the current study by estimating $\mathrm{C}$ from front crawl equation $\left(=0.228\left[10^{488 v}\right]\right.$, Capelli et al., 1998) at the same average velocity in 50, 100, and $200 \mathrm{~m}$ (e.g., $\sim 1.5$ vs. $\sim 1.7$; $\sim 1.2$ vs. $\sim 1.3$; and $\sim .9$ vs. $\left.\sim 1.0 \mathrm{~kJ} \times \mathrm{m}^{-1}\right)$. Despite that the economy is a feature of the skilled technique, other variables like age, anthropometry, training level, and engaged muscle mass can account for C difference among male swimmers (Chatard et al., 1990, 1991; Fernandes et al., 2006; Morris et al., 2016; Hellard et al., 2018), which seems to be the case for the comparisons with values from the current study.

However, the current findings are aligned with the statements on the $\mathrm{C}$ augmentation with swimming front crawl velocity increment at supramaximal velocities (Capelli et al., 1998), which was observed for both sexes. The increase in $\mathrm{C}$ with velocity has been demonstrated for young female swimmers with a different level of performance in $400 \mathrm{~m}$, while performing a common range of velocities below each group level from v400m (Chatard et al., 1991), for teenage women during the performance of 50, 100, 200, and $400 \mathrm{~m}$ (Zamparo et al., 2000), and between young competitive female swimmers performing $200 \mathrm{~m}$ with different stroke rate values (Morris et al., 2016). Although the $\mathrm{C}$ values for female swimmers are scarce for performances at supramaximal velocities, a single study demonstrated that young women spent 19,15 , and $10 \%$ less energy when compared to young men at $1.2,1.4$, and $1.6 \mathrm{~m} \times \mathrm{s}^{-1}$ (Zamparo et al., 2000), which were not, necessarily, the actual velocities for 400, 200, 100, and $50 \mathrm{~m}$. Therefore, the current findings can be useful to compare $\mathrm{C}$ measurement methods and analyze performance levels while swimming at actual 50, 100, and 200 m events.

For example, the average $\mathrm{C}$ values reported for high ranked young female swimmers at $1.4 \mathrm{~m} \mathrm{~s}^{-1}$ (or $\sim 103 \% \mathrm{vVO}_{2 \text { peak }}$ ) was $27.3 \mathrm{ml} \times \mathrm{m}^{-1}$ (Unnithan et al., 2009), which is $31 \%$ lower than the $\mathrm{C}$ estimated in the current study at the correspondent swimming intensity $\left(\sim 102 \% \mathrm{vV}_{2 \text { peak }}\right.$ at $\left.200 \mathrm{~m}\right)$ or $43 \%$ lower

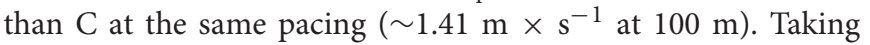
into account that these authors assessed only $\dot{\mathrm{VO}}_{2}$ response to estimate $\mathrm{C}$, and that anaerobic contribution to 200 and $100 \mathrm{~m}$ can reach $\sim 29$ and $\sim 46 \%$, respectively, for women (Almeida et al., 2020), these $C$ values can be considered equivalent. Indeed, the $\mathrm{C}$ values for women observed in the current study for $200 \mathrm{~m}$ are only $\sim 8 \%$ higher than the $\mathrm{C}$ for low trained level female swimmers $\left(\sim 13.6 \mathrm{~J} \times \mathrm{kg}^{-1} \times \mathrm{m}^{-1}\right)$ performing at $1.2 \mathrm{~m} \times \mathrm{s}^{-1}$ (or $\sim 103 \% \mathrm{vV}_{2 \text { peak }}$ ), but are $25 \%$ higher than $\mathrm{C}$ of high-trained level female swimmers $\left(\sim 11.7 \mathrm{~J} \times \mathrm{kg}^{-1} \times \mathrm{m}^{-1}\right)$ performing at the same absolute pacing $\left(1.2 \mathrm{~m} \times \mathrm{s}^{-1}\right)$ but at lower relative intensity ( $\sim 86 \%$ vنंO 2 peak $)$ (Fernandes et al., 2006). While the comparison with low-trained swimmers did not differ, since the

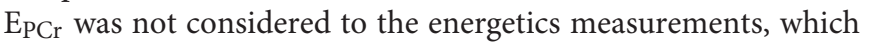
usually account for more than $\sim 10 \%$ at exercise rate (Sousa et al., 2013), the comparison to the high-trained woman highlights the importance of swimming economy to the athlete consolidation.

Moreover, the current findings also observed that the differences in $\mathrm{C}_{\text {Total }}$ between sexes during each distance were eliminated when expressed in body mass units, which is aligned to the reports for both sexes at the same absolute submaximal 
pacing (i.e., $1.3 \mathrm{~m} \times \mathrm{s}^{-1}$ ) but different exercise rate for men vs. women: $\sim 90$ vs. $\sim 98 \%$ vVंO $_{2 \text { peak }}$ (Fernandes et al., 2006). However, previous studies comparing both sexes at $100 \%$ $\mathrm{vV}_{2 \text { peak }}$ (Fernandes et al., 2005) or at different stroke rates and velocities (Morris et al., 2016) found higher C for men than women, which was considered an effect of high velocity or stroke rate achieved at $\dot{\mathrm{VO}}_{2 \text { peak }}$ in men and, therefore, different energy requirement compared to women. The current findings support that the higher $\mathrm{C}$ for young men than young women while performing 50 to $200 \mathrm{~m}$ can be attributed to the highest velocity performed by men, which is probably accounted to the larger hydrodynamic resistance (Zamparo et al., 2000, 2008).

The current study did not observe differences in $\mathrm{C}$ when scaled to the body mass, which may be occurred due to the paired supramaximal exercise rate where hydrodynamics compromises both sexes maximally and hence accounting less to explain the $\mathrm{C}$ values variation with velocity (Zamparo et al., 2000, 2008). Also, differences between sexes of C values at swimming circumstance $>100 \% v \dot{V O}_{2 \text { peak }}$, lasting 30-150 s, would be supported to the differences in $\mathrm{VO}_{2}$ adjustments to its maximum and the rate of anaerobic stores depletion, which have been theoretically demonstrated by comparing swimmers while swimming with different stroke technique or having no similar $\dot{\mathrm{VO}}$ 2peak level (di Prampero et al., 2008). In absence of this case, the technical proficiency (favoring women) and the energetic releasing (favoring men) would be balanced by a given similar $\mathrm{C}$ between sexes. However, this still remains in a theoretical scenery and could be explored in the future studies by analyzing swimmers with similar C.

Finally, this is the first study demonstrating that swimmers with the largest lean mass in the trunk and upper limb are less economical while performing 50 and $100 \mathrm{~m}$ because lean mass is related to high anaerobic $\mathrm{C}$, and swimmers with the largest lean mass in the lower limb should present more aerobic $\mathrm{C}$, whatever the sex. On the other hand, if $\mathrm{C}$ increases with swimming velocity demanding high metabolic energy (Zamparo et al., 2000, 2008; di Prampero et al., 2008), then lean mass content between swimmers is crucial to the improvement of short and middle distance performances, which is a sex-specific $\mathrm{C}$ statement complementing that reporting body mass and composition as explanatory variables for energy metabolism and performance differences between athletes from different maturation level (Hellard et al., 2018).

Inasmuch as the biological level of maturation for each sex-group was not determined in the current study, we are unable to refute the fact that maturation level has an effect on energetics and $\mathrm{C}$, and on the relation of these variables with lean mass. Thus, this is a limitation of the current findings, indicating that the interplay between lean mass and energy releasing could be an effect of maturation and not related to sex differences (Jürimäe et al., 2007) or, at least, suggesting limited transference to other age-groups. Although, swimmers were supposed to have similar status respective to each sexual developmental stage, as suggested to the low variability of lean mass, height, and body weight values in each sex-group (Zemel, 2013).
Furthermore, as traditional or specific resistance training can modify force-velocity relationship in muscle and neuromuscular coordination affecting swimming performance positively along with increasing lean mass (Crowley et al., 2017), it should therefore be highly recommended to explore in future studies the potential of muscle hypertrophy to improve swimming performance during supramaximal exercise rates. Taking all of these in consideration, the findings suggest young male and female swimmers can improve their actual conditioning level, and, therefore, their short and middle distances performances by following exercises planning to improve trunk and upper and lower limbs lean mass, enabling limbs muscles to attend for high $\mathrm{C}$ demands.

\section{CONCLUSION}

The current study observed sex independence on the profile of contribution and reliance of the energetics components during high intensity swimming performance. This evidence is favoring no constraints for the energetics capability of women to match men's energy balance and releasing during high intensity swimming performance. Moreover, current results about $\mathrm{C}$ are aligned to the notion that differences between sexes on energetics are related to body mass and composition, and therefore eliminated when scaled to body size dimensions. However, this finding refers to an analysis not encompassing toplevel athletes, but concern to swimmers in-preparation and with similar training experience and conditioning levels for which the differences in hydrodynamics and supramaximal exercise rates are minor. Finally, the specificities of each sex regarding the energetics and lean mass responses to training should be further explored in future studies engaging top-level swimmers from different age-groups.

\section{DATA AVAILABILITY STATEMENT}

The raw data supporting the conclusions of this article will be made available by the authors, without undue reservation.

\section{ETHICS STATEMENT}

The studies involving human participants were reviewed and approved by Ethics Committee of the São Paulo State University (Protocol 54372516.3.0000.5398). Written informed consent to participate in this study was provided by the participants' legal guardian/next of kin.

\section{AUTHOR CONTRIBUTIONS}

DM, TA, JR, FA, and DP conceived and designed the study. DM, TA, CV, ME, AM, JR, and DP conducted the experiments and analyzed the data. DM, TA, ME, AM, JR, FA, RF, and DP wrote 
the manuscript. All authors contributed to the article, read, and approved the manuscript.

\section{ACKNOWLEDGMENTS}

The authors would like to express our gratitude to the swimmers for their time and effort and the swimming teams for making both their infrastructures and staff available for the study. DP would like to thank São Paulo Research Foundation - FAPESP
(PROCESS 2016/04544-3 and 2018/16706-3) for the partial financial support, and ME to the Foundation for Science and Technology, I.P., Grant/Award Number UIDB/04748/2020. AM acknowledges the fellowship from Coordenação de Aperfeiçoamento de Pessoal de Nível Superior - Brazil (CAPES Finance Code 001). This manuscript was possible thanks to the scholarship granted from the Brazilian Federal Agency for Support and Evaluation of Graduate Education (CAPES), in the scope of the Program CAPES-PrInt, process number 88887.310463/2018-00, Mobility number 88887.580265/2020-00.

\section{REFERENCES}

Almeida, T. A. F., Pessôa Filho, D. M., Espada, M. A. C., Reis, J. F., Sancassani, A., Massini, D. A., et al. (2021). Physiological responses during high-intensity interval training in young swimmers. Front. Physiol. 12:662029. doi: 10.3389/ fphys.2021.662029

Almeida, T. A. F., Pessôa Filho, D. M., Espada, M. A. C., Reis, J. F., Simionato, A. R., Siqueira, L. O. C., et al. (2020). VO2 kinetics and energy contribution in simulated maximal performance during short and middle distance-trials in swimming. Eur. J. Appl. Physiol. 120, 1097-1109. doi: 10.1007/s00421-02004348-y

Baldari, C., Fernandes, R. J., Meucci, M., Ribeiro, J., Vilas-Boas, J. P., and Guidetti, L. (2013). Is the new aquatrainer ${ }^{\circledR}$ snorkel valid for $\dot{\mathrm{VO}} 2$ assessment in swimming? Int. J. Sports Med. 34, 336-344. doi: 10.1055/s-0032-1321804

Bangsbo, J., Gollnick, P. D., Graham, T. E., Juel, C., Kiens, B., Mizuno, M., et al. (1990). Anaerobic energy production and O2 deficit-debt relationship during exhaustive exercise in humans. J. Physiol. 422, 539-559. doi: 10.1113/jphysiol. 1990.sp018000

Bouwsema, M. M., Tedjasaputra, V., and Stickland, M. K. (2017). Are there sex differences in the capillary blood volume and diffusing capacity response to exercise? J. Appl. Physiol. 122, 460-469. doi: 10.1152/japplphysiol.00389.2016

Capelli, C., Pendergast, D. R., and Termin, B. (1998). Energetics of swimming at maximal speeds in humans. J. Appl. Physiol. 78, 385-393. doi: 10.1007/ s004210050435

Chatard, J. C., Lavoie, J. M., and Lacour, J. R. (1991). Energy cost of front crawl swimming in women. Eur. J. Appl. Physiol. 63, 12-16. doi: 10.1007/BF00760794

Chatard, J. C., Lavoie, J. M., and Lacourl, J. R. (1990). Analysis of determinants of swimming economy in front crawl. Eur. J. Appl. Physiol. 61, 88-92. doi: 10.1007/BF00236699

Chatard, J. C., Paulin, M., and Lacour, J. R. (1988). "Postcompetition blood lactate measurements and swimming performance: illustrated by data from a $400 \mathrm{~m}$ olympic record holder," in Swimming Science $V$, eds B. E. Ungerechts, K. Wilke, and K. Reischle (Champaign, IL: Human Kinetics), 311-316.

Cohen, J. (ed.) (1988). Statistical Power Analysis for the Behavioral Sciences. Hillsdale, NJ: L. Erlbaum Associates, doi: 10.4324/9780203771587

Crowley, E., Harrison, A. J., and Lyons, M. (2017). The impact of resistance training on swimming performance: a systematic review. Sports Med. 47, 2285-2307. doi: 10.1007/s40279-017-0730-2

di Prampero, P. E., Dekerle, J., Capelli, C., and Zamparo, P. (2008). The critical velocity in swimming. Eur. J. Appl. Physiol. 102, 165-171. doi: 10.1007/s00421007-0569-6

di Prampero, P. E., and Ferretti, G. (1999). The energetics of anaerobic muscle metabolism: a reappraisal of older and recent concept. Respir. Physiol. 118, 103-115. doi: 10.1016/s0034-5687(99)00083-3

Esbjörnsson, M., Sylven, C., Holm, I., and Jansson, E. (1993). Fast twitch fibres may predict anaerobic performance in both females and males. Int. J. Sports Med. 14, 257-263. doi: 10.1055/s-2007-1021174

Esbjörnsson-Liljedahl, M., Sundberg, C. J., Norman, B., and Jansson, E. (1999). Metabolic response in type I and type II muscle fibers during a 30-s cycle sprint in men and women. J. Appl. Physiol. 87, 1326-1332. doi: 10.1152/jappl.1999.87. 4.1326

Ferguson, C. J. (2009). An Effect size primer: a guide for clinicians and researchers. Prof. Psychol. Res. Pract. 40, 532-538. doi: 10.1037/a0015808

Fernandes, R., Billat, V., Cruz, A., Colaço, P., Cardoso, C., and Vilas-Boas, J. P. (2005). Has gender any effect on the relationship between time limit at VO2max velocity and swimming economy? J. Hum. Mov. Stud. 49, 127-148.

Fernandes, R. J., Billat, V. L., Cruz, A. C., Colaço, P. J., Cardoso, C. S., and VilasBoas, J. P. (2006). Does net energy cost of swimming affect time to exhaustion at the individual's maximal oxygen consumption velocity? J. Sports Med. Phys. Fitness 46, 373-380.

Figueiredo, P., Pendergast, D. R., Vilas-Boas, J. P., and Fernandes, R. J. (2013). Interplay of biomechanical, energetic, coordinative, and muscular factors in a $200 \mathrm{~m}$ front crawl swim. Biomed. Res. Int. 2013:897232. doi: 10.1155/2013/ 897232

Figueiredo, P., Zamparo, P., Sousa, A., Vilas-Boas, J. P., and Fernandes, R. J. (2011). An energy balance of the $200 \mathrm{~m}$ front crawl race. Eur. J. Appl. Physiol. 111, 767-777. doi: 10.1007/s00421-010-1696-Z

Gonjo, T., McCabe, C., Sousa, A., Ribeiro, J., Fernandes, R. J., Vilas-Boas, J. P., et al. (2018). Differences in kinematics and energy cost between front crawl and backstroke below the anaerobic threshold. Eur. J. Appl. Physiol. 118, 1107-1118. doi: 10.1007/s00421-018-3841-z

Gratas-Delamarche, A., Le Cam, R., Delamarche, P., Monnier, M., and Koubi, H. (1994). Lactate and catecholamine responses in male and female sprinters during a Wingate test. Eur. J. Appl. Physiol. Occup. Physiol. 68, 362-366. doi: 10.1007/BF00571458

Haizlip, K. M., Harrison, B. C., and Leinwand, L. A. (2015). Sex-based differences in skeletal muscle kinetics and fiber-type composition. Physiol 30, 30-39. doi: 10.1152/physiol.00024.2014

Hegge, A. M., Myhre, K., Welde, B., Holmberg, H. C., and SandbakK, O. (2015). Are gender differences in upper-body power generated by elite crosscountry skiers augmented by increasing the intensity of exercise? PLoS One. 10:e0127509. doi: 10.1371/journal.pone.0127509

Hellard, P., Pla, R., Rodríguez, F. A., Simbana, D., and Pyne, D. B. (2018). Dynamics of the metabolic response during a competitive $100 \mathrm{~m}$ freestyle in elite male swimmers. Int. J. Sports. Physiol. Perform. 13, 1011-1020. doi: 10.1123/ijspp. 2017-0597

Hill, D. W., and Vingren, J. L. (2011). Maximal accumulated oxygen deficit in running and cycling. Appl. Physiol. Nutr. Metab. 36, 831-838. doi: 10.1139/ h11-108

Hunter, S. K. (2016). The relevance of sex differences in performance fatigability. Med. Sci. Sports Exerc. 48, 2247-2256. doi: 10.1249/MSS.0000000000000928

Jürimäe, J., Haljaste, K., Cicchella, A., Lätt, E., Purge, P., Leppik, A., et al. (2007). Analysis of swimming performance from physical, physiological, and biomechanical parameters in young swimmers. Pediatr. Exerc. Sci. 19, 70-81. doi: $10.1123 /$ pes.19.1.70

Koons, N. J., Suresh, M. R., Schlotman, T. E., and Convertino, V. A. (2019). Interrelationship between sex, age, blood volume, and VंO2max. Aerosp. Med. Hum. Perform. 90, 362-368. doi: 10.3357/AMHP.5255.2019

Margaria, R., Edwards, H. T., and Dill, D. B. (1933). The possible mechanisms of contracting and paying the oxygen debt and the role of lactic acid in muscular contraction. Am. J. Physiol. 106, 689-714. doi: 10.1152/ajplegacy.1933.106.3. 689

Maud, P. J., and Shultz, B. B. (1986). Gender comparisons in anaerobic power and anaerobic capacity tests. Br. J. Sports Med. 20, 51-54. doi: 10.1136/bjsm.20.2.51

Medbo, J. I., Mohn, A. C., Tabata, I., Bahr, R., Vaage, O., and Sejersted, O. M. (1988). Anaerobic capacity determined by maximal accumulated O2 deficit. J. Appl. Physiol. 64, 50-60. doi: 10.1152/jappl.1988.64.1.50 
Miller, A. E. J., Macdougall, J. D., Tarnopolsky, M. A., and Sale, D. G. (1993). Gender differences in strength and muscle fiber characteristics. Eur. J. Appl. Physiol. Occup. Physiol. 66, 254-262. doi: 10.1007/bf00235103

Morris, K. S., Osborne, M. A., Shephard, M. E., Skinner, T. L., and Jenkins, D. G. (2016). Velocity, aerobic power and metabolic cost of whole body and arms only front crawl swimming at various stroke rates. Eur. J. Appl. Physiol. 116, 1075-1085. doi: 10.1007/s00421-016-3372-4

Mukaka, M. M. (2012). Statistics corner: a guide to appropriate use of correlation coefficient in medical research. Malawi Med. J. 24, 69-71.

Naughton, G. A., Carlson, J. S., Buttifant, D. C., Selig, S. E., Meldrum, K., Mckenna, M. J., et al. (1997). Accumulated oxygen deficit measurements during and after high-intensity exercise in trained male and female adolescents. Eur. J. Appl. Physiol. Occup. Physiol. 76, 525-531. doi: 10.1007/s004210050285

Nindl, B. C., Mahar, M. T., Harman, E. A., and Patton, J. F. (1995). Lower and upper body anaerobic performance in male and female adolescent athletes. Med. Sci. Sports Exerc. 27, 235-241.

Ogita, F., Hara, M., and Tabata, I. (1996). Anaerobic capacity and maximal oxygen uptake during arm stroke, leg kicking and whole-body swimming. Acta. Physiol. Scand. 157, 435-441. doi: 10.1046/j.1365-201X.1996.490237000.x

Ogita, F., Onodera, T., Tamaki, H., Toussaint, H. M., Hollander, A. P., and Wakayoshi, K. (2003). "Metabolic profile during exhaustive arm stroke, leg kick, and whole-body swimming lasting $15 \mathrm{~s}$ to $10 \mathrm{~min}$," in Biomechanics and Medicine in Swimming IX, ed. J. C. Chatard (Saint-Etienne: University of Saint-Etienne), 361-366.

Özyener, F., Rossiter, H. B., Ward, S. A., and Whipp, B. J. (2001). Influence of exercise intensity on the on-and off-transient kinetics of pulmonary oxygen uptake in humans. J. Physiol. 533, 891-902.

Peltonen, J. E., Hägglund, H., Koskela-Koivisto, T., Koponen, A. S., Aho, J. M., Rissanen, A. P. E., et al. (2013). Alveolar gas exchange, oxygen delivery and tissue deoxygenation in men and women during incremental exercise. Respir. Physiol. Neurobiol. 188, 102-112. doi: 10.1016/j.resp.2013.05.014

Pessoa Filho, D. M., Alves, F. B., Reis, J. F., Greco, C. C., and Denadai, B. S. (2012). $\dot{\mathrm{V} O} 2$ kinetics during heavy and severe exercise in swimming. Int. J. Sports Med. 33, 744-748. doi: 10.1055/s-0031-1299753

Pessôa Filho, D. M., Simionato, A. R., Siqueira, L. O. D. C., Espada, M. A., and Pestana, D. (2016). Influence of regional and whole-body composition on swimming performance and aerobic indices. Braz J of Sports Med 22, 195-199. doi: 10.1590/1517-869220162203151766

Reis, J. F., Alves, F. B., Bruno, P. M., Vleck, V., and Millet, G. P. (2012). Oxygen uptake kinetics and middle-distance swimming performance. J. Sci. Med. Sport. 15, 58-63. doi: 10.1016/j.jsams.2011.05.012

Ribeiro, J., Toubekis, A. G., Figueiredo, P., de Jesus, K., Toussaint, H. M., Alves, F., et al. (2017). Biophysical determinants of front crawl swimming at moderate and severe intensities. Int. J. Sports Physiol. Perform. 12, 241-246. doi: 10.1123/ ijspp.2015-0766

Robergs, R. A., Dwyer, D., and Astorino, T. (2010). Recommendations for improved data processing from expired gas analysis indirect calorimetry. Sports Med. 40, 95-111. doi: 10.2165/11319670-000000000-00000

Rosenthal, J. A. (1996). Qualitative descriptors of strength of association and effect size. J. Soc. Service Res. 21, 37-59. doi: 10.1300/J079V21N04_02

Rossiter, H. B., Ward, S. A., Kowalchuk, J. M., Howe, F. A., Griffiths, J. R., and Whipp, B. J. (2002). Dynamic asymmetry of phosphocreatine concentration and $\mathrm{O} 2$ uptake between the on-and off-transients of moderate-and highintensity exercise in humans. J. Physiol. 541, 991-1002. doi: 10.1113/jphysiol. 2001.012910

Russ, D. W., Lanza, I. R., Rothman, D., and Kent-Braun, J. A. (2005). Sex differences in glycolysis during brief, intense isometric contractions. Muscle Nerve 32, 647-655. doi: $10.1002 /$ mus. 20396

Sala, A., Webber, C. E., Morrison, J., Beaumont, L. F., and Barr, R. D. (2007). Whole-body bone mineral content, lean body mass, and fat mass measured by dual-energy $\mathrm{X}$ ray absorptiometry in a population of normal Canadian children and adolescents. Can. Assoc. Radiol. J. 58, 46-52.

Scheuermann, B. W., Hoelting, B. D., Noble, M. L., and Barstow, T. J. (2001). The slow component of $\mathrm{O} 2$ uptake is not accompanied by changes in muscle EMG during repeated bouts of heavy exercise in humans. J. Physiol. 531, 245-256. doi: $10.1111 /$ j.1469-7793.2001.0245j.x
Sousa, A., Figueiredo, P., Zamparo, P., Vilas-Boas, J. P., and Fernandes, R. J. (2013). Anaerobic alactic energy assessment in middle distance swimming. Eur. J. Appl. Physiol. 113, 2153-2158. doi: 10.1007/s00421-013-2646-3

Spencer, M. R., and Gastin, P. B. (2001). Energy system contribution during 200-to 1500 m running in highly trained athletes. Med. Sci. Sports Exerc. 33, 157-162. doi: 10.1097/00005768-200101000-00024

Stirling, J. R., Zakynthinaki, M. S., and Saltin, B. (2005). A model of oxygen uptake kinetics in response to exercise: including a means of calculating oxygen demand/deficit/debt. Bull. Math. Biol. 67, 989-1015. doi: 10.1016/j.bulm.2004. 12.005

Toussaint, H. M. (1990). Differences in propelling efficiency between competitive and triathlon swimmers. Med. Sci. Sports Exerc. 22, 409-415.

Toussaint, H. M., and Hollander, A. P. (1994). Energetics of competitive swimming: implications for training programs. Exerc. Sports Sci. Rev. 18, 384-405. doi: 10.2165/00007256-199418060-00004

Troup, J., Hollander, A., Bone, M., Trappe, S., and Barzdukas, A. (1992). "Performance-related differenced in the anaerobic contribution of competitive freestyle swimmers," in Biomechanics and Medicine in Swimming VI, eds D. MacLaren, T. Reilly, and A. Lees (London: E \& FN SPON), 271-278.

Unnithan, V., Holohan, J., Fernhall, B., Wylegala, J., Rowland, T., and Pendergast, D. R. (2009). Aerobic cost in elite female adolescent swimmers. Int. J. Sports Med. 30, 194-199. doi: 10.1055/s-0028-1104583

Wakayoshi, K., D’Acquisto, L., Cappaert, J., and Troup, J. (1995). Relationship between oxygen uptake, stroke rate and swimming velocity in competitive swimming. Int. J. Sports Med. 16, 19-23. doi: 10.1055/s-2007-972957

Weber, C. L., Chia, M., and Inbar, O. (2006). Gender differences in anaerobic power of the arms and legs-a scaling issue. Med. Sci. Sports Exerc. 38, 129-137. doi: 10.1249/01.mss.0000179902.31527.2c

Weber, C. L., and Schneider, D. A. (2002). Increases in maximal accumulated oxygen deficit after high-intensity interval training are not gender dependent. J. Appl. Physiol. 92, 1795-1801. doi: 10.1152/japplphysiol.00546.2001

Zacca, R., Azevedo, R., Ramos, V. R. Jr., Abraldes, J. A., Vilas-Boas, J. P., de Souza Castro, F. A., et al. (2020). Biophysical follow-up of age-group swimmers during a traditional three-peak preparation program. J. Strength Cond. Res. 34, 2585-2595. doi: 10.1519/JSC.0000000000002964

Zamparo, P., Capelli, C., Cautero, M., and Di Nino, A. (2000). Energy cost of front crawl swimming at supramaximal speeds and underwater torque in young swimmers. Eur. J. Appl. Physiol. 83, 487-491. doi: 10.1007/s004210000318

Zamparo, P., Capelli, C., and Pendergast, D. (2011). Energetics of swimming: a historical perspective. Eur. J. Appl. Physiol. 111, 367-378. doi: 10.1007/s00421010-1433-7

Zamparo, P., Lazzer, S., Antoniazzi, C., Cedolin, S., Avon, R., and Lesa, C. (2008). The interplay between propelling efficiency, hydrodynamic position and energy cost of front crawl in 8 to 19-year-old swimmers. Eur. J. Appl. Physiol. 104, 689-699. doi: 10.1007/s00421-008-0822-7

Zemel, B. (2013). Bone mineral accretion and its relationship to growth, sexual maturation and body composition during childhood and adolescence. World Rev. Nutr. Diet. 106, 39-45. doi: 10.1159/000342601

Conflict of Interest: The authors declare that the research was conducted in the absence of any commercial or financial relationships that could be construed as a potential conflict of interest.

Publisher's Note: All claims expressed in this article are solely those of the authors and do not necessarily represent those of their affiliated organizations, or those of the publisher, the editors and the reviewers. Any product that may be evaluated in this article, or claim that may be made by its manufacturer, is not guaranteed or endorsed by the publisher.

Copyright (c) 2021 Massini, Almeida, Vasconcelos, Macedo, Espada, Reis, Alves, Fernandes and Pessôa Filho. This is an open-access article distributed under the terms of the Creative Commons Attribution License (CC BY). The use, distribution or reproduction in other forums is permitted, provided the original author(s) and the copyright owner(s) are credited and that the original publication in this journal is cited, in accordance with accepted academic practice. No use, distribution or reproduction is permitted which does not comply with these terms. 